NBER WORKING PAPER SERIES

ASPIRATIONS AND INEQUALITY

Garance Genicot

Debraj Ray

Working Paper 19976

http://www.nber.org/papers/w19976

\author{
NATIONAL BUREAU OF ECONOMIC RESEARCH \\ 1050 Massachusetts Avenue \\ Cambridge, MA 02138 \\ March 2014
}

Thanks to Luís Felipe López-Calva, Joan Esteban, Kalle Moene, Alois Stutzer, Jean Tirole and four anonymous referees, as well as seminar participants at Cambridge, ColMex, EIEF, LAMES 2008, Maryland, Oxford, Washington University in St. Louis, Toulouse, Berlin, ThReD conferences at LSE and Brussels, the World Bank (DECRG and Conference on Aspirations, Poverty and Inequality), and the 2016 Laffont Lecture of the Econometric Society. Ray thanks the Einaudi Institute for Economics and Finance for its hospitality. Ray's research was funded by the National Science Foundation under grants SES-1261560 and SES-1629370. The views expressed herein are those of the authors and do not necessarily reflect the views of the National Bureau of Economic Research.

NBER working papers are circulated for discussion and comment purposes. They have not been peer-reviewed or been subject to the review by the NBER Board of Directors that accompanies official NBER publications.

(C) 2014 by Garance Genicot and Debraj Ray. All rights reserved. Short sections of text, not to exceed two paragraphs, may be quoted without explicit permission provided that full credit, including (C) notice, is given to the source. 
Aspirations and Inequality

Garance Genicot and Debraj Ray

NBER Working Paper No. 19976

March 2014, Revised December 2016

JEL No. D9,J62,015,O40

\begin{abstract}
$\underline{\text { ABSTRACT }}$
This paper develops a theory of socially determined aspirations, and the interaction of those aspirations with growth and inequality. The interaction is bidirectional: economy-wide outcomes determine individual aspirations, which in turn determine investment incentives and social outcomes. Thus aspirations, income and the distribution of income evolve jointly. When capital stocks lie in some compact set, steady states distributions must exhibit inequality and are typically clustered around local poles. When sustained growth is possible, initial histories matter. Either there is convergence to an equal distribution (with growth) or there is perennial relative divergence across clusters, with within-cluster convergence. A central feature that drives these results is that aspirations that are moderately above an individual's current standard of living tend to encourage investment, while still higher aspirations may lead to frustration.
\end{abstract}

Garance Genicot

Department of Economics

Georgetown University

ICC 570

Washington, DC 20057

and NBER

gg58@georgetown.edu

Debraj Ray

Department of Economics

New York University

19 West Fourth Street

New York, NY 10003

and University of Warwick

and also NBER

debraj.ray@nyu.edu 


\title{
ASPIRATIONS AND INEQUALITY ${ }^{1}$
}

\author{
Garance Genicot \\ Georgetown University \\ Debraj Ray \\ New York University and University of Warwick
}

December 2016

\begin{abstract}
This paper develops a theory of socially determined aspirations, and the interaction of those aspirations with growth and inequality. The interaction is bidirectional: economy-wide outcomes determine individual aspirations, which in turn determine investment incentives and social outcomes. Thus aspirations, income and the distribution of income evolve jointly. When capital stocks lie in some compact set, steady states distributions must exhibit inequality and are typically clustered around local poles. When sustained growth is possible, initial histories matter. Either there is convergence to an equal distribution (with growth) or there is perennial relative divergence across clusters, with within-cluster convergence. A central feature that drives these results is that aspirations that are moderately above an individual's current standard of living tend to encourage investment, while still higher aspirations may lead to frustration.
\end{abstract}

JEL Classification Numbers: J62, D9, O15, 040.

Keywords: Aspirations, reference points, inequality, income distribution

\section{INTRODUCTION}

In the 2014 general elections of India, the incumbent United Progressive Alliance was handed a resounding defeat by the National Democratic Alliance, led by the Bharatiya Janata Party. Yet in the two-term decade that the United Progressive Alliance governed India, GDP per capita grew at the impressive rate of $7.6 \%$ per year. As Ghatak, Ghosh, and Kotwal (2014) observe, "[G]rowth accelerated, Indians started saving and investing more, the economy opened up, foreign investment came rushing in, poverty declined sharply and building of infrastructure gathered pace ... [But a] period of fast growth in a poor country can put significant stress on the system which it must cope with. Growth can also unleash powerful aspirations as well as frustrations..."

This is a paper about aspirations, the individual incentives to invest, and the evolution of economic inequality. The topic of inequality needs little introduction. Within-country disparities have been on the increase - in some cases quite dramatically - in many parts of the developed and developing world, and the Indian example cited above is just one of many instances.

\footnotetext{
${ }^{1}$ Thanks to Luís Felipe López-Calva, Joan Esteban, Kalle Moene, Alois Stutzer, Jean Tirole and four anonymous referees, as well as seminar participants at Cambridge, ColMex, EIEF, LAMES 2008, Maryland, Oxford, Washington University in St. Louis, Toulouse, Berlin, ThReD conferences at LSE and Brussels, the World Bank (DECRG and Conference on Aspirations, Poverty and Inequality), and the 2016 Laffont Lecture of the Econometric Society. Ray thanks the Einaudi Institute for Economics and Finance for its hospitality. Ray's research was funded by the National Science Foundation under grants SES-1261560 and SES-1629370. Please address all correspondence to gg58@georgetown. edu and debraj.rayenyu.edu.
} 
The study of economic divergence has been conducted from several quarters; among them, nonconvexities, occupational choice, institutions and technological change. ${ }^{2}$ More recently, there has been some emphasis on psychological constraints to savings and accumulation that could generate poverty traps and widening inequality. ${ }^{3}$ Our paper fits into this last category.

Following Appadurai (2004) and Ray (1998, 2006), we describe a model of socially dependent "aspirations," one that incorporates both the inspiration of higher goals and the potential frustrations that can result. Both individual experience and the social environment condition aspirations. We address: (a) how aspirations are formed, (b) individual reactions to aspirations, and (c) the aggregation of behavior to derive society-wide outcomes.

On (a): we define utilities around "thresholds" and interpret those thresholds as aspirations. Aspirations are endogenous: they are influenced both by individual circumstances and the ambient income distribution. ${ }^{4}$ This social impact on aspirations may be "global" (for instance, an individual's aspirations may be related to the mean of the entire distribution) or "local" (for instance, an individual could be constrained by what she perceives of the distribution in some cognitive window). On (b): the crossing of an aspirational threshold generates an extra payoff. This "addon" payoff is defined on the difference between outcomes and aspirations, and affects individual incentives to invest and bequeath. Via these incentives, we describe both the encouragement and frustration that aspirations can create. This part of our model stands on its own (i.e., without any "general equilibrium" considerations) as an aspirations-based theory of poverty traps; see Propositions 2-4. We argue that the "best" aspirations are those that lie at a moderate distance from the individual's current situation, large enough to incentivize but not so large as to induce frustration. This is in line with evidence from cognitive psychology, sports, education, and lab experiments (see, e.g., Berger and Pope (2011), Goux, Gurgand, and Maurin (2014), Heath, Larrick, and Wu (1999) and Lockwood and Kunda (1997)) that goals that lie ahead — but not too far ahead - provide the best incentives. ${ }^{5}$

Finally, on (c): while social outcomes affect aspirations, those very aspirations influence - via the aggregation of individual decisions - the overall development of a society. As a result, aspirations and income (and the distribution of income) evolve together. Our main contribution is to embed the theory into a simple growth model with changing income distributions. In equilibrium, the overall income distribution influences individual aspirations, which in turn shape the distribution via individual choices. The feature, highlighted earlier, that the gap between aspirations and current standard of living can either encourage or frustrate investment (depending on the size of that gap) is a central force behind our results.

\footnotetext{
${ }^{2}$ See, e.g., Becker and Tomes (1979), Loury (1981), Dasgupta and Ray (1986), Freeman (1996), Banerjee and Newman (1993), Galor and Zeira (1993), Acemoglu (2002), Mookherjee and Ray (2003), Matsuyama (2004), Acemoglu and Robinson (2012), and Piketty (2014).

${ }^{3}$ See Appadurai (2004), Bernheim, Ray, and Yeltekin (1999, 2015) and Banerjee and Mullainathan (2010).

${ }^{4}$ See Stutzer (2004) and Macours and Vakis (2009) for evidence on the importance of social interactions in aspirations formation.

${ }^{5}$ To cite just one example from social psychology, LeBoeuf and Estes (2004) find that subjects score lower on trivia questions when first primed by self-listing similarities between them and Einstein (interpretable as raising their aspirations), relative to when not primed; and they score higher when asked to list the differences between them and Einstein (interpretable as lowering their aspirations) relative to when not primed.
} 
We study the interaction between aspirations and inequality in two environments. The first is a setting with bounded incomes. We define steady state income distributions: those in which the implied aspirations regenerate the same distribution with which we started. We show that such distributions cannot exhibit perfect equality, in contrast to the usual finding of income convergence. Compression of the wealth distribution leads to some individuals accumulating faster than others, destroying that compression. Specifically, a steady state income distribution in our model is typically bimodal. See Propositions 5 and 6 . The second environment allows for sustained growth, and assumes constant-elasticity payoff and a linear "A-K" production technology. Now initial conditions determine asymptotic behavior. When the initial income distribution is "equal enough," the economy converges to perfect equality, with all incomes ultimately growing at the same rate. This is akin to the standard convergence predictions of classical growth models. However, when the initial income distribution is unequal, the economy begins to develop clusters, and in lines with the findings of Piketty (2014) and others, inequality must progressively increase: under some conditions, the distribution across clusters never settles down, not even to relative stationarity. Yet there is convergence within clusters. See Propositions 7 and 8.

We provide a tractable model of socially determined aspirations though there are several related questions left to explore. In particular, we do not provide philosophical or evolutionary foundations for aspiration formation, or indeed for why people should have aspirations at all. Rather, we take these objects as primitives, and build on them. The particular application we have emphasized here concerns the evolution of income distributions, highlighting the endogenous feedback from distributions to aspirations, and the consequent impact of aspirations on investment and income.

At the other extreme, there is also the task of extending the aspirations model beyond the narrow economic sphere to which we've confined ourselves. We conclude the paper by discussing extensions to multidimensional aspirations and cross-group interactions, and how such extensions might bear on theories of collective action or social conflict; specifically, the use of targeted violence in such circumstances. ${ }^{6}$

\section{RELATED LiterATURE}

While we draw on Appadurai (2004) and Ray (1998, 2006), we specifically develop and build on the ideas laid down in an early working paper, Genicot and Ray (2009). Bogliacino and Ortoleva (2015) consider a model of socially determined aspirations similar to Genicot and Ray (2009). They assume that the aspiration threshold for everyone at any date is given by the common value of average income at that date. ${ }^{7}$ Like us, they are also interested in the evolution of economic inequality. The present paper is significantly different in that it handles a wide array of aspirationformation functions including those with bounded cognitive windows. Unlike in Bogliacino and Ortoleva (2015), aspirations systematically differ across incomes, and this heterogeneity plays a central role in the analysis.

\footnotetext{
${ }^{6}$ See, e.g., Mitra and Ray (2014) for an empirical account of Hindu-Muslim violence in India.

${ }^{7}$ See also Stutzer (2004), who discusses aspirations based on own income and average income. He then goes to empirically assess the behavior of such a function but does not use it in a behavioral model.
} 
The threshold-based formulation introduced in Genicot and Ray (2009) is also employed by Dalton, Ghosal, and Mani (2016). However, they study aspirations that are generated by private experiences, as do Gilboa and Schmeidler (1995) for aspiration-based satisficing in decision theory, and Karandikar et al. (1998) for aspiration-based learning in games. In contrast, for us, the social aspects of aspirations formation are central to the analysis, though we also incorporate private influences. The recent contribution by Besley (2015) studies yet another aspect of aspirations formation, one in which parents can deliberately affect the aspirations of their offspring in order to motivate them; this approach is connected to Bisin and Verdier (2000). In our model, individuals do not choose their level of aspirations. It is determined by their experience and the income distribution around them.

Our results contribute to a literature that explores the emergence and persistence of inequality, including nonconvexities (Galor and Zeira (1993), Matsuyama (2004)), occupational choice (Banerjee and Newman (1993), Freeman (1996), Mookherjee and Ray (2003)), institutions (Acemoglu and Robinson (2012), Bowles, Durlauf, and Hoff (2006)), endogenous risk-taking (Becker, Murphy, and Werning (2005), Ray and Robson (2012)), or marriage concerns (Cole, Mailath, and Postlewaite (1992). In particular, our paper is related to recent work on psychological traps due to lack of self-control (Banerjee and Mullainathan (2010), Bernheim, Ray, and Yeltekin $(1999,2015)$ ) or stress (Mani et al. (2013)). Our findings also relate to empirical studies of "twin-peaked" cross-country distributions of per-capita income; see (Durlauf and Johnson (1995) and Quah (1993, 1996)).

Our paper connects to the literature on reference points; e.g., prospect theory (Kahneman and Tversky (1979), Kőszegi and Rabin (2006) and Shalev (2000)) or models of habit formation (Carroll and Weil (1994), Overland, Carroll, and Weil (2000), Croix and Michel (2001) and Alonso-Carrera, Caball, and Raurich (2007)). In this literature, as in Dalton, Ghosal, and Mani (2016), the reference point is personally determined (say, by consumption history). As already mentioned, we emphasize both the social and personal determinants of aspirations. In this sense, our inquiry has more in common with the literature on status-seeking (see, e.g., Veblen (1899), Duesenberry (1949), Scitovsky (1976), Frank (1985), Robson (1992), Schor (1992), Clark and Oswald (1996), Corneo and Jeanne (1997), Corneo and Jeanne (1999), Cole, Mailath, and Postlewaite (1992), Hopkins and Kornienko (2006) and Ray and Robson (2012)). In these contributions, individuals care about their relative ranking in the distribution and these concerns could generate inequality.

There are, however, substantive differences between models of status-seeking and the aspirationsbased framework. At the heart of it is the fundamentally non-monotonic way in which individuals react to the gap between their aspirations and achievements. Perhaps there is a way to achieve the same effect in a status-seeking model, but to our knowledge this has not been done. (Indeed, such a formulation would need to define achievements relative to some target status, and then we would not be far from the aspirations model anyway.) In turn, this non-monotonicity has novel distributional and growth implications, such as the proclivity towards "within-cluster" convergence and "cross-cluster" inequality. Finally, the aspirations-based approach is conceptually different as well; for instance, it naturally lends itself to the study of limited cognitive windows in the formation of aspirations, or to the comparative roles played by personal and social circumstances. 


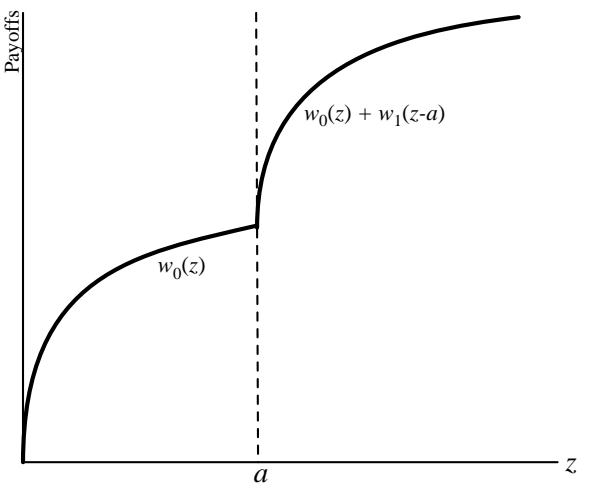

(A) Payoff Function

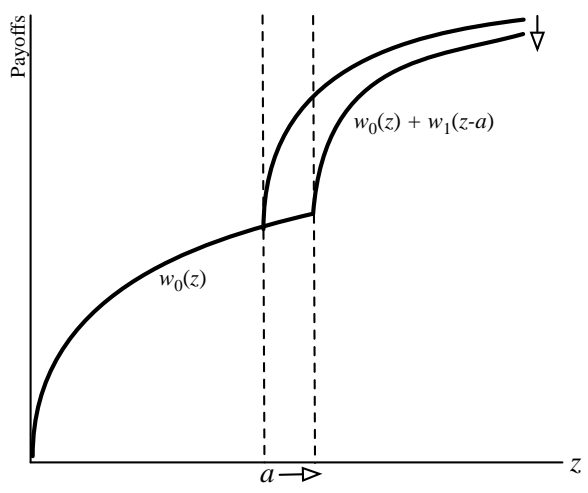

(в) Change in Aspirations

Figure 1. Aspirations AND PAYOFFs

\section{Aspirations, Wealth Distribution And Equilibrium}

3.1. An Intertemporal Model With Aspirations. Consider a society populated by a large number of single-parent single-child families. Each person lives for a single period. A parent-child sequence forms a dynasty. A typical member of any generation has a lifetime income (or wealth) $y$, and allocates $y$ over her lifetime consumption $c$ and investments to affect the wealth of her child $z$, so as to maximize payoff: $u(c)+w_{0}(z)+w_{1}(e)$.

The first of these three terms is the utility $u$ from own consumption $c$; increasing, smooth and strictly concave with unbounded steepness at zero. The second and third terms pertain to utility derived from the child's wealth $z$. The function $w_{0}$ is "intrinsic" parental utility derived from the wealth of the child. The function $w_{1}$ represents "milestone utility," the return that parents receive from the excess $e=\max \{z-a, 0\}$ of their child's wealth $z$ over the aspiration $a$ of the parent. An aspiration thus acts as a reference point for the agent. Section 3.2 will show how it is shaped by the agent's income and the ambient distribution of income. We assume that $w_{0}$ and $w_{1}$ are increasing, smooth and strictly concave.

Figure 1, Panel A, depicts the function $w_{0}(z)+w_{1}(\max \{z-a, 0\})$. We make five remarks. First, as in Stutzer (2004) and Luttmer (2005), higher current aspirations never increase current payoffs (Panel B). Whether or not it increases the payoffs to the next generation depends on how marginal incentives to accumulate are affected; more below. Second, one can write down a variant of this model with several aspirational thresholds (an " $a$-vector"), with such milestones also shaped by the overall distribution. Third, our results are robust to more general $w_{1}$-functions that incorporate disutility in departing downwards from $a$. It is only crucial that the aggregated function $w_{0}+w_{1}$ display sufficient nonconcavity around the aspirational threshold. Fourth, it is easy to incorporate variants in which the crossing of the threshold engenders a jump in utility; i.e., $w_{1}(0)>0$. Finally, the intrinsic term $w_{0}$ is defined on the wealth of the child, but it is not a value function in the sense of dynamic programming. Writing such a version of this problem is possible but complicated, as it requires parents to forecast the endogenously determined aspirations of all their descendants. 
3.2. The Formation of Aspirations. Two approaches, by no means mutually exclusive, connect aspirations to economic outcomes and so bring the theory full circle. One possibility is to take an entirely private viewpoint: only one's personal experiences determine future goals. This is the approach in Carroll and Weil (1994), Karandikar et al. (1998), Croix and Michel (2001), Kőszegi and Rabin (2006), Alonso-Carrera, Caball, and Raurich (2007) and Dalton, Ghosal, and Mani (2016). In this literature, the loop that runs from reference points to behavior and back to reference points is entirely internal to the individual.

In contrast, economic models of status achieve closure by using social outcomes external to the individual. A broad array of possibilities is captured under the specification

$$
a=\Psi(y, F),
$$

where $F$ is the society-wide distribution of lifetime incomes in the current generation. ${ }^{8}$ Thus aspirations can depend both on personal and social circumstances, though everyone has the same aspirations formation function. This allows for substantial heterogeneity, induced endogenously via varying wealths. Consider the following assumptions:

[Regularity] $\Psi$ is continuous and nondecreasing in $y$.

[Scale-Invariance] $\Psi\left(\lambda y, F^{\lambda}\right)=\lambda \Psi(y, F)$ for all $\lambda>0$, where $F^{\lambda}$ stands for the distribution when all incomes in $F$ are scaled by $\lambda: F^{\lambda}(\lambda y)=F(y)$ for all $y$.

[Range Boundedness] $\min \{y, \min F\} \leq \Psi(y, F) \leq \max \{y, \max F\}$ for all $F$ and $y$.

[Social Monotonicity] For any $y, \Psi\left(y, F^{\prime}\right) \geq \Psi(y, F)$ when $F^{\prime}$ weakly dominates $F$ in the sense of first-order stochastic dominance, with strict inequality if the dominance is strict. ${ }^{9}$

The first two assumptions are self-explanatory. The third, range-boundedness, asserts that aspirations are social constructs and so located within the full gamut of observed incomes in society. ${ }^{10}$ These three assumptions are maintained throughout the paper. Finally, social monotonicity states that an increase in incomes everywhere else, leaving a particular individual's income unchanged, raises that individual's aspirations. We will be explicit whenever this restriction is imposed, and we discuss the assumption further in Section 5.4.

3.3. Remarks on Socially Dependent Aspirations. A very general class of functions satisfies our restrictions. For instance, all these conditions are met if aspirations are given by some weighted average of $y$ and the mean of $F$. But we do not intend to suggest that all of $F$ enters the individual's "aspirations window." The individual's income positions her within her social

\footnotetext{
${ }^{8}$ It is, of course, also possible to adopt a specification in which the anticipated distribution of wealth over future generations drives aspirations. A previous version of the paper, see Genicot and Ray (2009), discusses and compares the two approaches. We are comfortable with either model, but adopt the current approach because the resulting structure is fully recursive and far more friendly to numerical computation.

${ }^{9}$ First-order stochastic dominance means that $F^{\prime}(y) \leq F(y)$ for all $y$. Under strict dominance, strict inequality holds for all $y$ such that $F(y)>0$ and $F^{\prime}(y)<1$.

${ }^{10}$ Formally, we define $\Psi(y, F)$ for all $y$ and $F$, even for $y$ outside the support of $F$, but ask that aspirations not wander out of the overall range of possibilities encompassed by $y$ and $F$.
} 
environment, summarized by $F$. In particular, it may circumscribe what she "sees" of $F$. For instance, as in Ray (2003), an aspirations window could be "formed from an individual's cognitive world, her zone of 'similar', 'attainable' individuals ...".

Such similarity - at least in economic space — can be accommodated by allowing a person to place cognitive weight only on some population quantile around her. Incomes within the window would then be used to generate aspirations at $y$. Or cognitive truncations could result from the fact that individuals do not look to anyone poorer then them to form their aspirations: they have "upward looking" aspirations as suggested by Duesenberry (1949).

Individuals might also use occupation, caste, religion, or geography, to form their windows; see, e.g., Akerlof and Kranton (2000), Munshi and Myaux (2006), Esteban and Ray (2008) and Mitra and Ray (2014). Our model can be extended to study group-based aspirations, in which the population consists of several subgroups, or "ethnicities," and their incomes enter the aspiration formation function in different ways. With no cross-identity interactions, such an extension is trivial as it would simply represent several co-existing copies of our model. With interactions, fresh and interesting considerations would arise.

3.4. Dynastic Equilibrium With Aspirations. We embed aspirations formation into a standard growth model. An individual divides her wealth $y_{t}$ between consumption $c_{t}$ and a bequest $k_{t}$, so that $y_{t}=c_{t}+k_{t}$. That bequest yields wealth for the next generation: $y_{t+1}=f\left(k_{t}\right)$, where $f$ is a smooth, increasing and concave function. That fresh wealth is aggregated into a distribution function for the next generation. For each date $t$ and wealth $y$, we have $a_{t}=\Psi\left(y_{t}, F_{t}\right)$. Let $\Phi\left(y_{t}, a_{t}\right)$ be the set of maximizers of

$$
u\left(y_{t}-k(z)\right)+w_{0}(z)+w_{1}\left(\max \left\{z-a_{t}, 0\right\}\right)
$$

over $z \in\left[0, f\left(y_{t}\right)\right]$, where $k(z) \equiv f^{-1}(z)$. An equilibrium from some initial distribution $F_{0}$ is a sequence of income distributions $\left\{F_{t}\right\}$ such that for every $t, F_{t+1}$ is generated from $F_{t}$ by some transition probability $p_{t}$; i.e.,

$$
F_{t+1}(z)=\int_{0}^{z} p_{t}(y,[0, z]) d F_{t}(y)
$$

where $p_{t}$ agrees with $\Phi_{t}$ and $F_{t}$ : for almost every $y$ under $F_{t}$, Supp $p_{t}(y,.) \subseteq \Phi_{t}\left(y, \Psi\left(y_{t}, F_{t}\right)\right)$.

The following proposition is a trivial recursive exercise:

Proposition 1. An equilibrium exists.

3.5. Benchmark with No Aspirations. In a benchmark with no aspirations, an individual would choose $z$ to maximize $u(y-k(z))+w_{0}(z)$, where we recall that $k(z)=f^{-1}(z)$. Define

$$
d(y) \equiv-\frac{u^{\prime}(y-k(y))}{f^{\prime}(k(y))}+w_{0}^{\prime}(y) .
$$

To avoid uninteresting cases, assume that the system pushes away from zero income; i.e.,

$$
d(y)>0 .
$$

for $y>0$ and small enough. We maintain this condition throughout. 


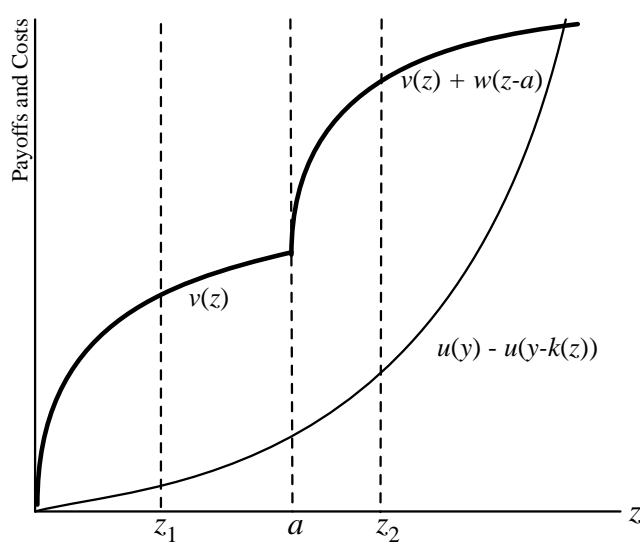

(A) Costs and Benefits

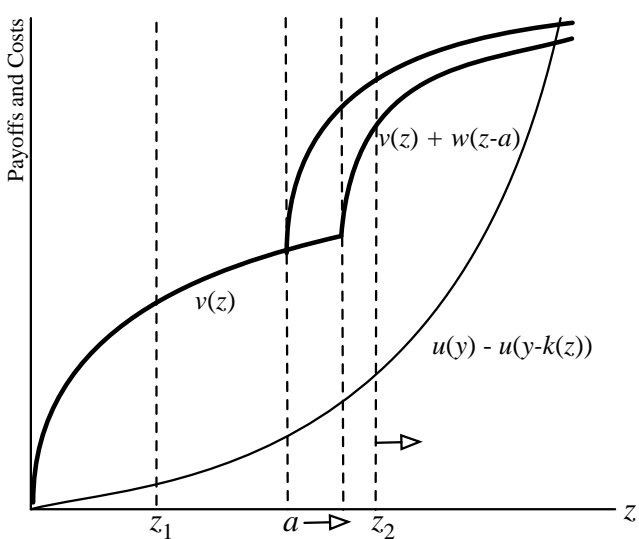

(B) Change in $a$

Figure 2. The Choice of Future Wealth.

At a stationary income $y^{*}$, the corresponding choice of continuation income $z$ equals $y^{*}$. If positive, it is described by the condition $d(y)=0$. There could be multiple stationary incomes, or none. We impose the condition:

$$
d(y) \text { is strictly decreasing in } y \text { whenever } d(y) \leq 0 .
$$

This implies, in particular, that the benchmark stationary income is unique, whenever it exists. ${ }^{11}$ This purges our benchmark model of possible inequalities in wealth that might arise from a "super-normal" response of child wealth to parental wealth.

\section{Satisfaction And Frustration}

Return to our model, in which expression (2), $u\left(y_{t}-k(z)\right)+w_{0}(z)+w_{1}\left(\max \left\{z-a_{t}, 0\right\}\right)$, is maximized. In Figure 2, the horizontal axis plots the choice of future wealth $z$, while the vertical axis records various benefits and costs. The benefit that accrues from next generation's wealth is given by $w_{0}(z)+w_{1}\left(e_{1}\right)$, where $e_{1}=\max \{z-a, 0\}$ is the excess (if any) of wealth over the threshold $a$. The cost is the sacrifice of current utility, which we can write as $u(y)-u(y-k(z))$, with a standard convex shape. Panel A of Figure 2 plots both these functions. Given income and aspirations, our maximization problem seeks a continuation income $z$ that produces the largest vertical distance between these two curves.

By the concavity of benefits to the left and right of $a$, there can be at most one "local" solution on either side of $a$. Finding an optimal solution involves comparing these two local solutions, that is, solving at most two interior first order conditions

$$
w_{0}^{\prime}\left(z_{0}\right)=u^{\prime}\left(y-k\left(z_{0}\right)\right) / f^{\prime}\left(k\left(z_{0}\right)\right)
$$

\footnotetext{
${ }^{11}$ It is easy enough to write down specific functional forms that satisfy this requirement. For instance, if $f(k)=$ $A k^{\alpha}$, then [D] holds whenever $-u^{\prime \prime}(c) c / u^{\prime}(c) \leq(1-\alpha)$ for all consumption levels $c$.
} 
and

$$
w_{0}^{\prime}\left(z_{1}\right)+w_{1}^{\prime}\left(z_{1}-a\right)=u^{\prime}\left(y-k\left(z_{1}\right)\right) / f^{\prime}\left(k\left(z_{1}\right)\right),
$$

the former if $z_{0}<a$ and the latter if $z_{1}>a$, and picking the one with higher payoff. ${ }^{12}$

4.1. Satisfied and Frustrated Aspirations. Say that the aspiration $a$ is satisfied if the chosen optimal solution exceeds $a$, and frustrated if it falls short of $a$. The slight ambiguity in this definition will be excused as the optimal choice of $z$ will be generically unique, with multiple solutions possible only for knife-edge values of $(y, a)$. See Proposition 2 below.

We make two remarks. First, notice that if an aspiration is satisfied, the income threshold is achieved in the very next period. This simplistic outcome is very easy to modify. If each generation lives several periods, a "satisfied aspiration" need not be satisfied immediately: wealth will be built up over the lifetime of the generation. Second, suppose that an individual has failed aspirations $a$, and is asked what her aspirations are. She may not report that failed yardstick (as her aspiration), even though it is the relevant threshold against which she has arrived at her current situation. We continue to use the term "aspirations" for these reference points, but the distinction is important both conceptually and empirically.

4.2. The Effect of Aspirations and Wealth on Investment. Consider a change in aspirations for some individual with given income. Such changes could be fueled by growth in ambient incomes. Or they may stem from the rise of mass media that brings particular socioeconomic groups into focus, thus affecting aspirations. ${ }^{13}$

When aspirations are close to zero, the optimal solution must strictly exceeds aspirations, and so they are satisfied. As long as aspirations remain in the "satisfaction zone," an increase in aspirations incentivizes growth: investment rises with aspirations. But there is an aspiration threshold $a^{*}$ (illustrated in Panel A of Figure 3) when there is a sudden turnaround from satisfaction to frustration: this switch will be accompanied by a discontinuous fall in investment; inspect (6) and (7). Once in the "frustration zone," investment becomes insensitive to further increases in aspirations. Proposition 2 formalizes this discussion:

Proposition 2. For any given initial wealth, there is a unique threshold value of aspirations below which aspirations are satisfied, and above which they are frustrated. As long as aspirations are satisfied, chosen wealth grows with aspirations. Once aspirations are frustrated, chosen wealth becomes insensitive to aspirations.

The insensitivity of chosen wealth to aspirations (once frustrated) is an artifact of the extreme minimality of the model. In the Online Appendix, we describe a natural extension that causes investment to decline with rising aspirations, once aspirations are frustrated.

\footnotetext{
${ }^{12}$ Formally, by (4) and $u^{\prime}(0)=\infty$, a solution $z_{0}$ always exists to (6). If $z_{0} \geq a$, then an interior solution $z_{1}$ to (7) also exists, and it is the global solution. If $z_{0}<a$, and (7) fails for any $z_{1}>a$, then $z_{0}$ is the global solution. If a solution to (7) does exist for $z_{1}>a$, then choose the solution with higher payoff.

${ }^{13}$ See Jensen and Oster (2009) and Ferrara, Chong, and Duryea (2012) for evidence on how cable television can expose people to different lifestyles, thereby affecting their aspirations and fertility preferences.
} 


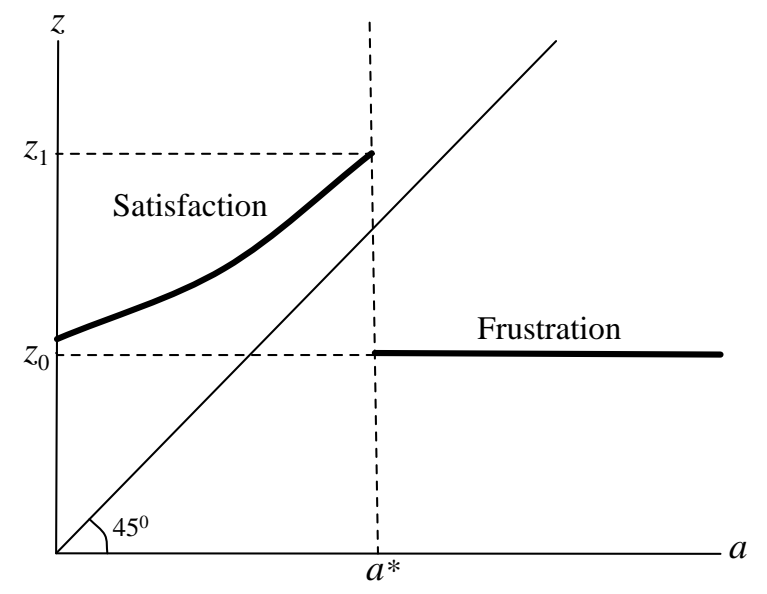

Figure 3. Response of InVESTMENT to Aspirations.

A variant of Proposition 2 applies not just to changing aspirations under some given wealth, but more generally to the ratio of aspirations to wealth. The scale-invariance of aspirations permits us to examine this not just for absolute levels but for rates of investment, and so for growth rates along the cross-section of individual wealths. To do so, we introduce an important special case of our model that is particularly conducive to the study of endogenous growth. Call it the constant elasticity growth model. It has the following components. First, we impose an "A-K" setting in which the production function is linear:

$$
f(k)=\rho k
$$

where $\rho>1$ is some constant return on capital holdings. This formulation accommodates exogenous labor income in every period. We can also include a credit limit on borrowing based on future labor income; it will make no difference to the results. ${ }^{14}$

Next, we assume that utilities are constant-elasticity, with the same elasticity for each utility indicator: $:^{15}$

$$
u(c)=c^{1-\sigma}, w_{0}(z)=\delta z^{1-\sigma}, \text { and } w_{1}(e)=\delta \pi e^{1-\sigma}
$$

where $\sigma \in(0,1), \delta>0$ is a measure of discounting, $\pi>0$ is a measure of the additional value of crossing the aspiration, and $e$ is the excess of $z$ over aspirations.

The expositional advantage of the constant elasticity growth model is that, in the absence of aspirations, bequests are proportional to wealth and growth rates are constant across the cross-section

\footnotetext{
${ }^{14}$ As in Bernheim, Ray, and Yeltekin (2015), if each generation earns a constant labor income $\ell$ in addition to receiving bequests, then $y_{t}=f_{t}+[\rho \ell /(\rho-1)]$, where $f_{t}$ is financial wealth. If she can borrow some fraction $(1-\lambda)$ of future income, then that translate into a lower bound on total wealth $y$, given by $B=\lambda \rho \ell /(\rho-1)$.

${ }^{15}$ Given constant elasticity, the use of a common elasticity $\sigma$ for the utility and aspirational components is unavoidable. Indeed, imagine scaling up aspirations and income together. If the elasticities differ, then at least one of these terms will either become relatively insignificant or unboundedly dominant. To retain the relative importance of both intrinsic consumption and aspirations, we use the same elasticity for each function.
} 
of wealths. We can therefore be sure that any cross-sectional variation in growth rates stems entirely from aspirations alone. We now describe the growth incidence curve, a relationship that links baseline income or wealth to subsequent rates of growth.

To this end, note that an individual with starting wealth $y$ and aspirations $a$ will choose continuation wealth $z$ to maximize

$$
\left(y-\frac{z}{\rho}\right)^{1-\sigma}+\delta\left[z^{1-\sigma}+\pi(\max \{z-a, 0\})^{1-\sigma}\right] .
$$

Let $r \equiv a / y$ denote the aspirations ratio: the ratio of aspirations to starting wealth. The maximization in (10) is equivalent to choosing a growth factor $g \equiv z / y$ that maximizes

$$
\left(1-\frac{g}{\rho}\right)^{1-\sigma}+\delta\left[g^{1-\sigma}+\pi(\max \{g-r, 0\})^{1-\sigma}\right] \text {. }
$$

We solve this problem just as in the general case. First write down the first order condition under the assumption that aspirations are met; that is, $g \geq r$. The corresponding growth factor $g(r) \equiv z / y$ is given by the solution to

$$
\left(1-\frac{g(r)}{\rho}\right)^{-\sigma}=\delta \rho\left[g(r)^{-\sigma}+\pi(g(r)-r)^{-\sigma}\right] .
$$

Note that there is a unique solution $g(r)$ to this equation in the region $(r, \infty)$ as long as this region is "reachable," which it will be provided $\rho>r .{ }^{16}$ Moreover, it is easy to check that $g(r)$ is strictly increasing in $r$. That is, analogous to Proposition 2, aspirations spur growth as long as aspirations are met. The alternative is to entirely ignore aspirations, which yields (via the usual first order condition), the growth factor $g$ that solves:

$$
\left(1-\frac{g}{\rho}\right)^{-\sigma}=\delta \rho \underline{g}^{-\sigma}
$$

If $g>r$, then the $g(r)$-solution is optimal at $y$ (because the latter "includes" the aspirational payoffs while the construction of $\underline{g}$ does not). On the other hand, if $\underline{g}<r$, then the individual must compare payoffs from the two alternative choices given by (12) and (13). ${ }^{17}$

Proposition 3. In the constant elasticity growth model, there is a unique $r^{*}>1$ such that for all wealth-aspiration pairs $(y, a)$ with $r \equiv a / y>r^{*}$, continuation wealth grows by $g$, and for all $(y, a)$ with $r \equiv a / y<r^{*}$, continuation wealth grows by $g(r)$. This value $g(r)$ increases in $r$, and is strictly larger and bounded away from $\underline{g}$; that is, $\lim _{r \rightarrow 0} g(r)>\underline{g}$.

The proposition states that if the aspirations ratio is high enough, aspirations are frustrated and growth (or possibly decay) occurs at rate $g$. As the ratio falls, there is a threshold $r^{*}$ at which the "upper solution" to condition (12) dominates the "lower solution" to condition (13), and the growth rate jumps up. The end-point condition (4) implies that growth rates are positive and therefore that this jump threshold lies above 1 . Thereafter, growth rates fall again as the

\footnotetext{
${ }^{16}$ If $\rho>r$, then starting at income $y$ it will be possible to produce more than $a: \rho y>a$.

${ }^{17}$ That is, she checks if $\left(1-\frac{g(r)}{\rho}\right)^{1-\sigma}+\delta\left[g(r)^{1-\sigma}+\pi(g(r)-r)^{1-\sigma}\right]>\left(1-\frac{g}{\rho}\right)^{1-\sigma}+\delta \underline{g}^{1-\sigma}$, chooses $g(r)$ if this inequality holds, and $\underline{g}$ otherwise.
} 


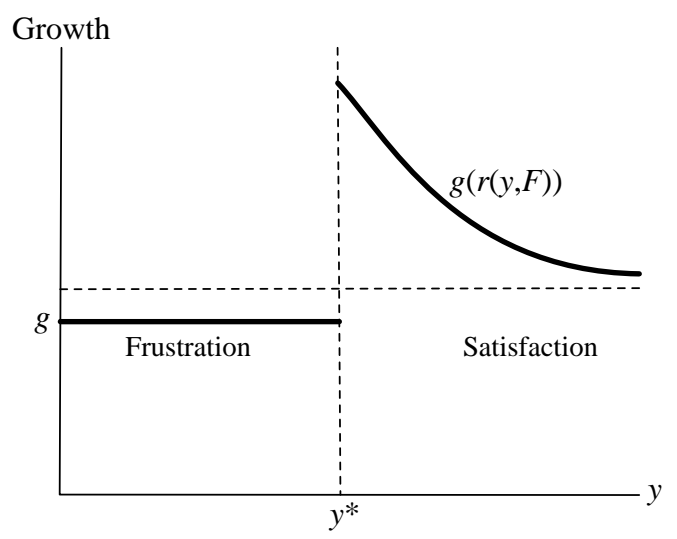

Figure 4. Growth Factors as a Function of initial Wealth.

aspirations ratio continues to fall, but because of the additional marginal payoff bestowed by aspirations utility, never come down to the original "frustration rate" $\underline{g}$.

Notice that this proposition says nothing about initial incomes, but matches initial ratios of aspirations to income with subsequent rates of growth. The proposition does translate into a growth incidence curve across the cross-section of incomes once we can connect initial incomes to aspirations ratios. Our assumptions provide some additional mileage to pin these movements down:

Observation 1. If aspirations are scale-invariant and socially monotone, then the aspirations ratio $r(y, F) \equiv \Psi(y, F) / y$ is strictly decreasing in y for each $F$.

Observation 1 combines immediately with Proposition 3 to yield

Proposition 4. In the constant elasticity growth model, assume that aspirations are scale-invariant and socially monotone. Vary initial income y along some distribution F. Then there is a threshold $y^{*}$ such that the growth factor is $g$ as long as $y<y^{*}$, jumps up at $y^{*}$ and thereafter declines in $y$, but remains strictly larger and bounded away from $\underline{g}$.

Figure 4 illustrates. With socially monotone aspirations the frustrated will constitute the poorest segment of the population, so that roughly speaking, the growth incidence curve is inverted-U shaped. The underlying idea that aspirations that are "reachable" serve to inspire, while still higher aspirations can generate frustration, is the central argument in Ray (1998, 2006), which we formalize here and will later apply to evolving income distributions. It echoes Tocqueville's account of the French Revolution, in which he repeatedly stressed the point that greater economic wealth among the middle classes brought the privileges of the very rich into full view. And so it was that "[t]he French found their position insupportable, just where it had become better ..." In summary, "[i]t is not always that from going from bad to worse that a society falls into revolution;" de Tocqueville (1856).

More recent examples are not hard to find. We began by mentioning the Indian elections of 2014. India's growth since the 1990s heralded the rise of an economically powerful urban class. It is certainly consistent with a story of burgeoning aspirations with salubrious effects on investment. 
But it is also true that large sections of the population were effectively delinked from the growth process (see Banerjee and Piketty (2005), Deaton and Drèze (2002) and Drèze and Sen (2013)). Along with the success stories that foreign investors so like to hear, there is a subtext of apathy and despair, violence and conflict. Whether the potential for frustration caused by rising aspirations played a central role deserves more investigation. But the observations are prima facie consistent with such a story.

Conceptually, this central point separates our theory somewhat from that of Appadurai (2004). Appadurai speaks of an aspirations failure in terms of a failed "capacity to aspire." In the theory here, there is no such failure. Rather, societal conditions induce overly demanding aspirational reference points on some segments of that society. What fails is not the aspiration, but the ability to live up to it. This is in line with recent literature which argues that lowering the aspirations of low income students to more reachable levels reduces the likelihood of dropping out of school in the US (Kearney and Levine (2014)) and in France (Goux, Gurgand, and Maurin (2014)). ${ }^{18}$ This discussion suggests caution in the empirical implementation of the theory, urging researchers to properly distinguish between the absence of aspirations, and the frustration induced by bars that are set too high.

\section{The Joint Evolution of Aspirations And InCOMES}

In the previous section, we emphasized some partial effects of aspirations and wealth on the subsequent growth of incomes. Because aspirations and incomes evolve jointly, these effects intertwine as an equilibrium sequence of income distributions $\left\{F_{t}\right\}$ (Section 3.4). There are natural questions that one can ask of such an interaction. For instance: (i) Is there persistent inequality in "steady state"? (ii) What is the relationship between initial inequality and subsequent growth? (iii) How does inequality evolve along a growth path?

The first question is naturally suited to a setting in which incomes lie in some bounded interval, while the other questions pertain to a setting in which sustained growth is possible.

5.1. Bounded Incomes and Stationary States. Consider the setting of Section 3.4, and impose the end-point restriction $f(x)<x$ for all $x$ large enough, which bounds wealth as in the Solow model. A stationary state is a distribution $F^{*}$ on positive wealths such that each dynasty replicates its starting wealth generation after generation. It implies (but is not necessarily implied by) a steady state: a distribution that replicates itself period after period. Under a steady state, dynasties might "cross paths," generating persistent mobility but with an unchanging distribution. The Online Appendix discusses these concepts further, and proves the existence of steady states.

Proposition 5. If aspirations are range-bound, no steady state can involve perfect equality.

This proposition comes from the convexification of utility caused by aspirations. ${ }^{19}$ Rangeboundedness implies that when incomes converge to each other, aspirations must lie in this

\footnotetext{
${ }^{18}$ The importance of keeping aspirations attainable is also an important consideration for the policies studied in Beaman et al. (2012) or Bernard et al. (2014).

${ }^{19}$ While such convexification could be outweighed by some other form of concavity in the system, such as the curvature of the production function, our model rules out this possibility by juxtaposing a fresh source of utility as
} 
narrow range as well. However, when incomes are very close to current aspirations, the marginal utility of accumulation is high in one direction and low in the other, and the system must push away from this neighborhood. Whether it pushes upwards or downwards will depend, as before, on a comparison with the two locally optimal choices on either side of the current aspiration level. But the essential point is that the system cannot stay where it is. The only way to have a steady state is to have a diversity of incomes in it. ${ }^{20}$

How seriously we view this result depends on one's intuition about marginal utility as one departs from incomes close to aspirations. Aspiration-fulfillment implies that an important goal has been reached, and to the extent that there is some fundamental satisfaction that depends on the crossing of that goal, and an important notion of failure on not reaching it, local convexity is not an unrealistic property, and our model has that property.

Proposition 5 is related to the literature on evolving income distributions. ${ }^{21}$ The closest relationship is to endogenous inequality, in which equality is destabilized by forces that move the system away from global clustering. In Freeman (1996) and Mookherjee and Ray (2003), this happens because productive factors are imperfect substitutes, so that a variety of occupations with different costs and returns must be populated in equilibrium. Together with imperfect capital markets, this implies that in steady state, there must be persistent inequality. In a different context, Becker, Murphy, and Werning (2005) and Ray and Robson (2012) argue that endogenous risk-taking can also serve to disrupt equality, as relative status-seeking effectively "convexifies" the utility function at high levels of clustering.

5.2. Bimodality. A stationary distribution of income must be bimodal: ${ }^{22}$

Proposition 6. Assume that aspirations are range-bound, scale-invariant and socially monotone. Then a stationary state is concentrated on just two positive values of incomes.

This proposition tells us that a stationary state distribution $F^{*}$ takes the form of a two-point distribution $\left(y_{\ell}, y_{h}, p\right)$, where $y_{\ell}<y_{h}$ and $p$ is the population weight on low-income earners $y_{\ell}$. Aspirations at $y_{\ell}$ must be frustrated, and those at $y_{h}$ must be satisfied. This proposition is related to parallel results about the missing middle class in Genicot and Ray (2009) and Bogliacino and Ortoleva (2015), though in these papers it is assumed that aspirations are common to all (and equal to the distributional mean), whereas in the present formulation the aspirations function is significantly more general.

the aspiration level is crossed (the function $w_{1}$ ) on top of the existing utility from progeny income (the function $w_{0}$ ), thereby creating a kink that "dominates" any degree of (smooth) curvature in $f$.

${ }^{20}$ In the Online Appendix, we remark on an extension to the case of exogenous technical progress in this bounded Solow-like setting.

${ }^{21}$ These focus on the emergence and persistence of inequality, and variously emphasize nonconvexities (Galor and Zeira (1993), Matsuyama (2004)), occupational choice (Banerjee and Newman (1993), Freeman (1996), Mookherjee and Ray (2003)), institutions (Acemoglu and Robinson (2012), Bowles, Durlauf, and Hoff (2006)), endogenous risktaking (Becker, Murphy, and Werning (2005), Ray and Robson (2012)), and the "twin-peaks" structure of per-capita income (Durlauf and Johnson (1995) and Quah (1993, 1996)).

${ }^{22} \mathrm{We}$ are not aware of a similar result for steady state distributions. 


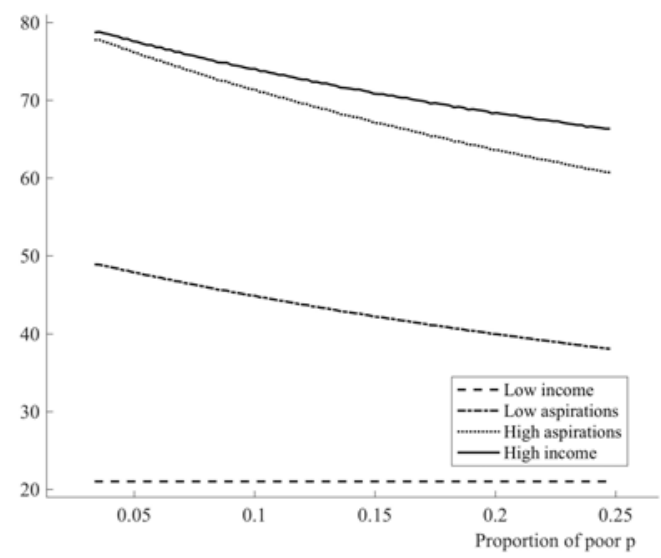

Figure 5. Income Gaps and Poor Proportions Across Stationary States.

There could be more than one solution to $\left(y_{\ell}, y_{h}, p\right)$. The Online Appendix contains a discussion on the possible solutions. Across these, there is a relationship between the proportion of lowincome earners, and the income gap between high and low incomes. Specifically, as one moves from a stationary state with a high proportion $p$ of low-incomes to another with a smaller $p$, the income gap $y_{h}-y_{\ell}$ must generally widen, because the aspirations of the "satisfied rich" rise, generating higher investment. This potential tradeoff between poverty and inequality is illustrated in the following example.

Example 1. Utilities are of the constant-elasticity form introduced in (9), with $\sigma=0.8, \delta=0.8$ and $\pi=1$. Let $f(k, \theta)=(A / \beta) k^{\beta}$, where $\beta=0.55$ and $A=4$. Aspirations are the average of one's own income and the mean income. We study the class of all (bi-modal) stationary states. The lower "frustrated" income will be determined by the benchmark model and is invariant over steady states. But there is a range of steady states with different values of high income $\left(y_{h}\right)$ and population proportions $(p)$. A smaller "poor population" is also associated with a higher income for the rich and greater inequality. Notice that only values of $p$ between $p_{\min }=0.03$ and $p_{\max }=0.25$ are possible in steady state. Figure 5 shows the high income $y_{h}$ and the level of aspiration as a function of $p$ in steady state. The high incomes steadily decline in the proportion of the poor.

To be sure, Proposition 6 is not meant to be taken literally: convergence to degenerate poles is an obvious artifact (analogous to the Solow prediction of a single income level in steady state). When there are stochastic shocks, the distribution will always be dispersed, as in the extension of the standard growth model by Brock and Mirman (1972) and others. We could easily introduce such shocks into the model at hand. The following example does just that.

Example 2. Assume the same preference parameters as in Example 1, but introduce noise in the production function. Let $f(k, \theta)=\theta(A / \beta) k^{\beta}$, where $\beta=0.8, A=4$ and $\theta$ is a shock with mean $1 .{ }^{23}$ Beginning with an initial uniform distribution of income and iterating the distribution

\footnotetext{
${ }^{23}$ Specifically, we suppose that $\theta$ follows a lognormal distribution. The qualitative results do not depend on the magnitude of the noise term, though in general, the degree of clustering must rise as the variance of the shock falls.
} 


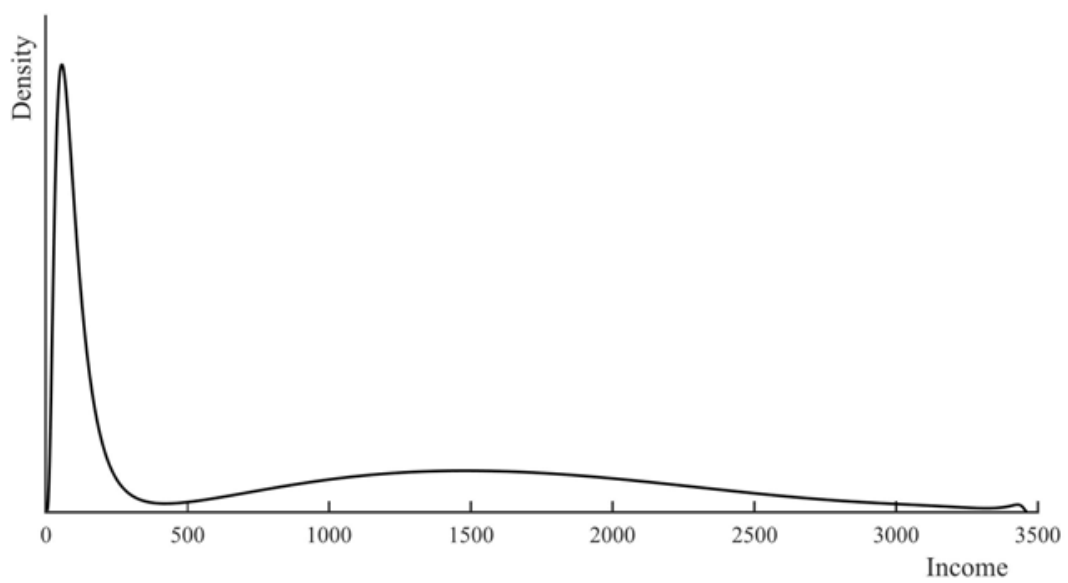

Figure 6. Bimodality in a Stationary State.

over several periods, the simulated distributions converge rapidly to a bimodal distribution shown in Figure 6 where the only mobility is due to the noise in the production function. ${ }^{24}$

There is evidence of clustering in the income distribution of various countries, including the United States (see Pittau and Zelli (2004), Sala-i Martin (2006) and Zhu (2005)), and especially across countries (Durlauf and Johnson (1995), and Quah $(1993,1996)){ }^{25}$ These authors make a strong case for local clustering in the world income distribution and argue that convergence is a local phenomenon "within the cluster" but not globally. Quah refers to these local clusters as "convergence clubs." We should also observe that bimodality is not particularly sacrosanct: for instance, group-based aspirations within or across ethnic groups or other partitions of the population would increase the number of clusters.

5.3. Growth and Inequality. We now turn to a different scenario which accommodates endogenous growth. To this end, we return to the constant elasticity growth model introduced in Section 4.2. In that model, all utility indicators are constant-elasticity with the same elasticity, and the production function is linear, so that in the benchmark model without aspirations, balanced-growth would result and inequality would remain constant.

Our starting point is some initial distribution of wealth; call it $F_{0}$. Initial aspirations are given by the mapping $a_{0}(y)=\Psi\left(y, F_{0}\right)$ for every income $y$ in the support of $F_{0}$. An individual with income $y$ will choose continuation wealth $z$ to maximize

$$
\left(y-\frac{z}{\rho}\right)^{1-\sigma}+\delta\left[z^{1-\sigma}+\pi\left(\max \left\{z-a_{0}(y), 0\right\}\right)^{1-\sigma}\right] .
$$

Recalling the analysis of Section 4.2, two options must be compared. The higher of the choices involves the growth factor that solves equation (12). This solution, which we denote by $g(r)$,

\footnotetext{
${ }^{24}$ In the figures, we smoothed the simulated distribution using the density estimator "ksdensity" for Matlab. In the absence of noise, the distribution concentrates on two levels on income: 95 and 1, 779 .

${ }^{25}$ See also Henderson, Parmeter, and Russell (2008), Canova (2004) and Pittau, Zelli, and Johnson (2010).
} 
depends on baseline wealth $y$ but only via the aspirations ratio $r=a_{0}(y) / y$; see Section 4.2. The lower choice involves a growth factor of $g$, which solves (13): this choice is entirely independent of $y$.

Proposition 7. Consider the constant-elasticity growth model. Assume that aspirations are range-bound, scale-invariant and socially monotone. Let $F_{0}$ be some initial distribution of wealth with compact support. Then there are just two possibilities:

1. Convergence To Perfect Equality: All wealths grow asymptotically at the rate $g(1)-1$, and normalized incomes $y_{t} / g(1)^{t}$ converge to a single point independent of $y_{0} \in \operatorname{Supp} F_{0}$.

Or there is

2. Persistent Divergence: $F_{t}$ "separates" into two components. There is a critical income level $y^{*}$ in the interior of the support of $F_{0}$ such that all incomes below $y^{*}$ change thereafter by the growth factor $\underline{g}$. All incomes initially above $y^{*}$ grow by some asymptotic factor $\bar{g}>\underline{g}$, with $\bar{g}-1>0$. Moreover, there is normalized convergence of these incomes: $y_{t} / \bar{g}^{t}$ converges to the same limit irrespective of $y_{0}$, as long as $y_{0}$ exceeds $y^{*}$. Overall, relative inequality never settles: despite the within-group convergence, it increases without bound.

Growth Comparison: $g<\bar{g} \leq g(1)$, so that overall growth is lower under divergence than under convergence.

Proposition 7 significantly narrows the way in which the dynamics of an income distribution can evolve. There are only two possibilities. In the first of these, the initial distribution has a high level of equality, so that even the lowest income level is not frustrated by the aspirations generated under $F_{0}$. That may be a tall order, but if it is met, then indeed all incomes converge to perfect equality with sustained growth. Thus the basin of attraction for an equal steady state with growth is a relatively equal society to begin with.

If that condition is not met, then the second possibility arises. Lower incomes fall short of aspirations, the economy turns bimodal and inequality increases. Moreover, that inequality never stops increasing, even in relative terms, with the income ratio between the satisfied and the frustrated steadily rising. However, there is growth-rate convergence among the "haves," and there is even level convergence (after normalizing by their limit growth rate) ${ }^{26}$

Example 3. To illustrate Proposition 7, we use the same preferences as in Example 1. Aspirations are given by an average of individual income and mean income. Production is linear and deterministic with $\rho=2.1$. Figure 7 plots the evolution of log income of the poorest individual and at every 10th percentile thereafter, up to the richest individual in an economy of 1000 . Higher curves represent richer individuals. Panel A uses an initial uniform distribution with narrow range, and generates convergence to equality with all incomes and aspirations growing at a common rate. We show the panel by normalizing trajectories by this limit growth factor, so that convergence can be clearly seen.

\footnotetext{
${ }^{26}$ The assumed constant-elasticity of utility makes these results particularly transparent, but as long as we use any utility function that allows for perpetual growth, we do not believe that the results of within-cluster convergence and cross-cluster divergence would change. What would change would be the constancy of growth rates over time for the frustrated, or the existence of an asymptotic rate of growth for the satisfied.
} 


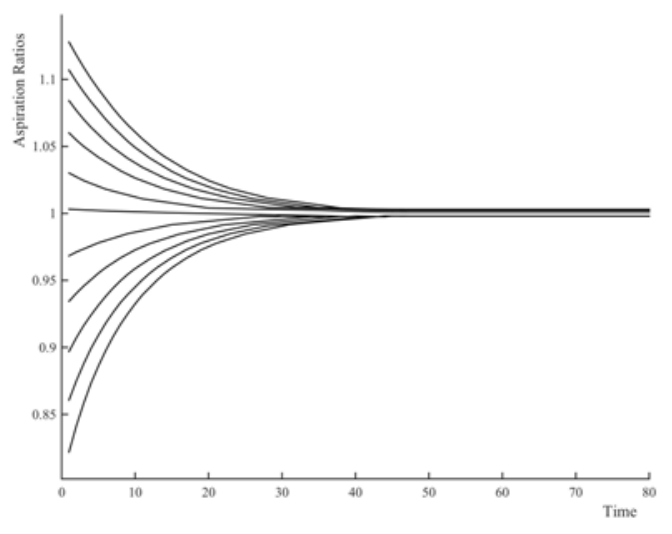

(A) Equal Initial Distribution (growth-normalized)

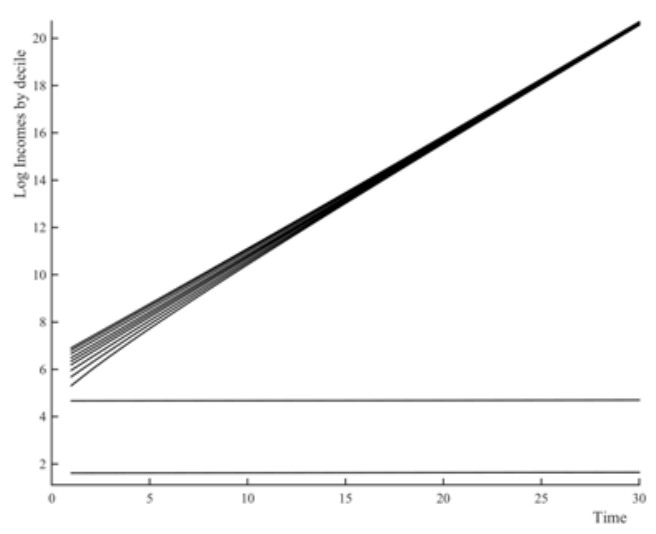

(B) Unequal Initial Distribution (log-linearized)

Figure 7. An Illustration of Proposition 7.

In Panel B we start with a uniform distribution over a wide range and end up with divergence. About $15 \%$ of the individuals choose the low growth rate $g$; their aspiration ratios progressively increase over time. The remainder choose a higher growth rate and in the limit, the growthnormalized incomes of all these individuals converge. However, overall growth is lower than that ultimately experienced in the more equal society of Panel A.

Other factors also affect the "chances" of equality. The Online Appendix shows that higher rates of return, a larger weight on aspirational utility, or lower aspirations functions $\Psi(y, F)$ are conducive to equality, as are aspirations that are less responsive to the distribution.

We make two more remarks to end this Section. First, it is of some interest that in the Solow setting, perfect equality cannot be a steady state while a bimodal distribution can. Here, perfect equality can be sustained with a constant rate of exponential growth. On the other, and again in contrast to the Solow setting, an unequal distribution with a constant degree of relative inequality cannot persist with growth: that inequality will need to widen over time, in line with recent observations made by Piketty (2014) and his coauthors.

Second, perfect equality exhibits the highest rate of growth compared to the asymptotic growth of any other configuration. This latter rate is some convex combination of a growth factor of $g<g(1)$ for frustrated individuals, and an asymptotic growth factor that is at best $g(1)$ for the satisfied individuals. (It should be noted, however, that an unequal society is temporarily capable of growing faster. For instance, in Case 2, the overall growth factor is a combination of factors for various aspiration ratios $g(r)$, where $r$ begins below 1 and ends above 1 . By suitably choosing the initial distribution, it is easy to construct an example in which this combination initially exceeds $g(1)$. However, that excess cannot persist.)

5.4. Cognitive Windows and Social Monotonicity. Of the different assumptions that underly Proposition 7, one merits particular examination. This is the social monotonicity condition, which states that for given individual income, aspirations must rise when all other incomes in the 


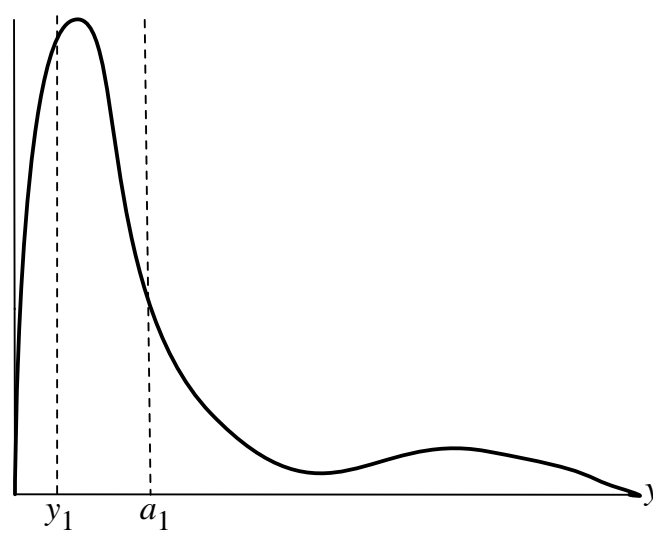

(A) Distribution With Low Income

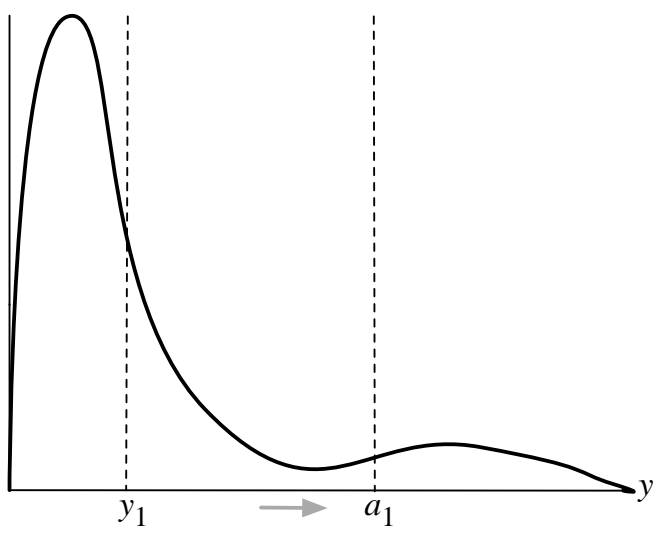

(B) Distribution with High Income

Figure 8. Possible Failure of Social Monotonicity .

society increase. In the presence of the scale-invariance assumption (which is truly innocuous), social monotonicity generates a tight restriction: over the cross-section of an income distribution, individual aspirations cannot climb faster than income. This was formalized as Observation 1. It is this property that implies the bimodal clustering in Proposition 6, and drives the proof of Proposition 7.

If individuals react to the entire distribution of incomes, the assumption of social monotonicity is natural: if every income is "visible," an increase in all incomes should raise individual aspirations, and social monotonicity is satisfied. However, as discussed in Section 3.3, individuals can have aspirations "windows" that ignore or put little weight on some parts of the distribution. The following example demonstrates why social monotonicity may be too restrictive an assumption when individuals exhibit such "cognitive truncations."

Example 4. Suppose that aspirations are given by the conditional mean of income above one's own income; i.e., $\Psi(y, F)=\mathbb{E}_{F}(x \mid x \geq y)$. Call this the case of upper mean aspirations. Consider the situation depicted in Figure 8. In the first panel, the upper mean for a person with income $y_{1}$ is located at $a_{1}$. Now move to the second panel by increasing income, so that the large mass of individuals who were within the cognitive window of $y_{1}$ now disappear. Aspirations can now shoot up; see the second panel of Figure 8. By Observation 1, we see that social monotonicity must be violated in this example. Indeed, using scale invariance, this example can played "in reverse" by decreasing all incomes, keeping individual income fixed. Note that aspirations rise as incomes come down.

5.4.1. Examples Without Social Monotonicity. To see the possible issues that might arise when attempting to extend Proposition 7 in the absence of social monotonicity, consider the following examples of aspirations windows. All examples will use the constant elasticity growth model, and aspirations are assumed to be scale-invariant and range-bound.

Example 5. Upper Mean Aspirations and Balanced Growth. Suppose again, as in Example 4, that aspirations are given by the upper mean for every income. We can now look for, and find, 
a distribution that is both non-degenerate and generates balanced growth at a factor $g>g$, a situation that is ruled out in Proposition 7.

Observation 2. Assume upper mean aspirations. Then balanced growth with growth factor $g>g$ is possible if (and only if) the distribution of normalized incomes $y /(1+g)^{t}$ is Pareto, and in particular has unbounded support:

$$
F\left(\frac{y}{[1+g]^{t}}\right) \equiv F(w)=1-(A / w)^{r /(r-1)}
$$

for all $w \geq A$ and $(A, r)$ such that $r \in\left(1, r^{*}\right]$.

See Online Appendix for a proof. Notice that social monotonicity is not satisfied: the aspirations ratio is constant over the entire range of incomes in the support of $F$. This example can be extended to also generate balanced-growth distributions in which every agent is frustrated, so that everyone grows (or decays) at the frustration rate.

The construction in the example - or in its extension where all agents are frustrated - must rely on unbounded distributions. But this is not true of our next example.

Example 6. Local Income Windows and Balanced Growth. Suppose that aspirations are determined only by incomes "near" one's own incomes, thereby becoming completely "isolated" if there are no such incomes. Call this the local income neighborhood model. Specifically, suppose that for some $\beta>0, \Psi(y, F)$ is completely insensitive to the distribution outside the local range $[y(1-\beta), y(1+\beta)]$, for every $y$.

Observation 3. In the local income neighborhood model, balanced growth is possible from a distribution with compact support, and no individual remains frustrated forever.

In the local income neighborhood model, perennial frustration is impossible. The reason is simple: given the fixed income-defined width of the cognitive window, other individuals who grow faster than me must eventually disappear from my aspirations window. (See Online Appendix for a formal proof.) It is then easy to see how isolated clusters of individuals, all with the same income within each cluster but income levels different enough across clusters that they do not enter each other's window, result in balanced growth. Example 6 therefore permits balanced growth even under initial distributions with bounded support, but at the expense of assuming the possibility of total isolation. The local income neighborhood model assumes an extremely segregated world in which no individual "sees" any individuals with incomes that are too different. That seems strong.

Example 7. Aspirations Windows and Relative Mobility. When aspirations ratios climb with incomes, income-crossings are possible. Imagine that the distribution at any date places point mass on three levels of income $y^{1}>y^{2}>y^{3}$. Suppose that aspirations windows are such that (i) the rich at $y^{1}$ only see each other, (ii) the middle-class at $y^{2}$ see $y^{1}$ and have frustrated aspirations, and (iii) the poor at $y^{3}$ see the middle-class but not the rich, and have satisfied aspirations. These aspirations windows could be truncated on an income basis, as in the previous example, or on a percentile basis. In this example, assume the rich are satisfied and grow at some factor, call it $g$. Assume the middle-class are frustrated and grow at factor $\underline{g}$, and that the poor are satisfied and grow at factor $g^{+}$. Typically, $g^{+}>g>\underline{g}$. 
The example is now completed by two requirements: we suppose that

$$
y^{2} g=y^{3} g^{+} \text {and } y_{t}^{3} g=y_{t}^{2} \underline{g} .
$$

Then the resulting distribution is identical to a distribution in which all incomes have grown by $g$. The scale-invariance of aspirations implies that nothing has changed, save for the middle-class and the poor who have exchanged identities. The normalized distribution stays the same, while dynasties trade places endogenously along an infinite set of dates. Now, such infinite crossings are, in some sense, non-generic, as they impose requirements on the distributional configuration that cannot be met except via the fortuitous choice of model parameters and/or initial conditions. That said, one can construct even more complex examples of sustained infinite crossings. While one suspects that similar considerations of genericity apply to those cases, a formal analysis to that effect remains an open question.

It should be noted, however, that two dynasties can only cross if one is frustrated and one is satisfied. If both are frustrated, a crossing is impossible as they both must evolve at the rate $g$. The fact that a crossing is also impossible when both dynasties are satisfied is a more subtle observation, and it is formalized as Lemma 3 in the Appendix.

5.4.2. Extending Proposition 7. In light of the previous examples and observations, it is of interest to see which core features of Proposition 7 survive the dropping of social monotonicity. We consider a weaker restriction, based on two ideas: (i) that higher rather than lower incomes affect aspirations, and (ii) that income "crossings" can generate counterintuitive changes in aspirations, as individuals move in and out of cognitive windows.

Specifically, for any $F$, let $F_{-}(y)$ denote the left-hand limit of the distribution at $y$. Suppose that $F^{\prime}$ weakly dominates $F$. If $y$ is the highest income in $F$, then we retain the weak version of social monotonicity: we ask that $\Psi\left(y, F^{\prime}\right) \geq \Psi(y, F)$. For lower income levels, we ask that $\Psi\left(y, F^{\prime}\right) \geq \Psi(y, F)$ only if there are no crossings "from below," i.e., $F_{-}^{\prime}(y)=F_{-}(y)$. Finally, we impose the strict inequality $\Psi\left(y, F^{\prime}\right)>\Psi(y, F)$ if, in addition, $F^{\prime}$ strictly dominates $F$ above $y$ : $F^{\prime}(x)<F(x)$ for all $x>y$ with $F^{\prime}(x)<1$. Say that aspirations are minimally monotone if all these conditions are satisfied.

Minimal monotonicity is weaker than social monotonicity because of the no-crossing implicit in the requirement $F_{-}^{\prime}(y)=F_{-}(y)$. That is, the condition only applies when incomes that are strictly less than $y$ remain strictly less. Otherwise, an income crossing might worsen the conditional distribution of incomes that an individual looks up to. ${ }^{27}$ So, for instance, minimal monotonicity does not restrict the behavior of aspirations in the case of the proportional increase in Example 4. Indeed, while the specification of "upper mean aspirations" used there failed social monotonicity, it can be shown to satisfy minimal monotonicity. The Online Appendix proves this property for a broad class of aspirations formation functions that are "upward looking," including those that have cognitive windows also truncated above. What is important is that individuals are always cognizant of some incomes higher than theirs whenever such incomes exist. Such a

\footnotetext{
${ }^{27}$ This also explains why we do not impose the restriction on the highest income. There were no incomes to "look up to" to begin with, so that the new higher incomes does not have any paradoxical effect.
} 
requirement is inconsistent with the situation in Example 6, where the use of an income-based cognitive truncation permits each income cluster to be entirely segregated from the others. ${ }^{28}$

The following proposition characterizes the dynamics of an income distribution under this weaker assumption of local monotonicity. To state it, define an income crossing (in equilibrium) at date $t$ by a pair of incomes $\left(y_{t}, y_{t}^{\prime}\right)$ with $y_{t}<y_{t}^{\prime}$, but $y_{t+1} \geq y_{t+1}^{\prime}$.

Proposition 8. Consider the constant-elasticity growth model. Assume that aspirations are range-bound, scale-invariant and minimally monotone. Let $F_{0}$ be some initial distribution of wealth with compact support. Then there are just three possibilities:

1. Convergence To Perfect Equality: All wealths grow asymptotically at the rate $g(1)-1$, and normalized incomes $y_{t} / g(1)^{t}$ converge to a single point independent of $y_{0} \in \operatorname{Supp} F_{0}$.

2. Persistent Divergence: Over time, the income distribution "separates" into two components, with the measure of frustrated individuals converging to a positive limit. Their incomes grow at rate $g-1$. Among the satisfied, there is a common asymptotic growth factor $\bar{g}>g$, with $\bar{g}-1>0$. Moreover, there is normalized convergence of these incomes: $y_{t} / \bar{g}^{t}$ converges to the same limit irrespective of $y_{0}$. Relative inequality increases without bound. Also, $g<\bar{g} \leq g(1)$, so that overall growth is slower than under convergence.

3. Infinite Crossings: there are income crossings across a positive measure of income pairs over an infinite subsequence of dates, which is potentially compatible with balanced growth and ever-widening inequality (though not convergence to equality).

Proposition 8 parallels Proposition 7 but is different in two ways. First, whereas in Proposition 7 the identities of the frustrated are pinned down from date 0 , this is not so in the current proposition, where a frustrated sub-population emerges over time. We find this version more realistic. The second difference lies in the presence of a possibility that Proposition 7 eliminates: that there are indefinite crossings of income ranks, as in Example 7. Such a state of affairs is incompatible with convergence to equality: by range-boundedness, all individuals would be satisfied after finite time, and as Lemma 3 in the Appendix shows, there cannot be crossings among the satisfied. But infinite crossings are compatible with balanced growth (cf. Example 7) or widening inequality. We conjecture - but have not proved - that balanced growth can be an outcome only in non-generic cases.

Proposition 8 is proved by showing that if Case 3 does not apply, so that after some date there are no more crossings, then either Case 1 or 2 must hold. Our central observation is that past that date, once an individual is frustrated, her state of frustration is permanent. Proposition 3 states that a frustrated individual exhibits the lowest growth rate of all observed growth rates. If we renormalize the new income distribution by dividing by this lowest growth rate, then, post renormalization our individual's income is unchanged, while all other incomes must be no lower. Moreover, because there are no crossings, no previously poorer person has higher renormalized income. In the formal proof, we apply minimal monotonicity to conclude that her aspirations are no lower in the renormalized distribution. By scale-invariance, we can now "un-renormalize"

\footnotetext{
${ }^{28}$ That is, the truncation (if any) will need to be defined in terms of population; e.g., awareness of the immediate richer decile.
} 
the new distribution to conclude that her new aspirations ratio is no lower than it was before. So our individual's frustration must continue. This yields a monotonicity property for the fraction of frustrated individuals: that fraction cannot decline over time, and must therefore converge. ${ }^{29}$

Among the frustrated, there is no level convergence, but all individuals grow at the same factor $g$. But everyone can't be frustrated: by range-boundedness, the aspirations ratio of the richest cannot exceed one and must be satisfied. Invoking Proposition 3, we see that the satisfied exhibit a strictly higher rate of growth. Since there are no more crossings, the frustrated remain at the bottom of the distribution. Hence, if the distribution converges to a positive mass of frustrated individuals, there is ever-widening inequality, which gives us Case 2. At the same time, there is convergence among the satisfied, so overall the distribution becomes increasingly polarized into a two-class society.

Of course, it is possible that no one is frustrated to begin with. But then - once normalized by the growth rate of the richest - there is level convergence this time among all individuals in the population, which is Case 1. There is also balanced growth in the limit, of course, but - unlike Example 6 - that balanced growth requires equality.

\section{CONCLUSION}

This paper develops a theory of socially determined aspirations. We define aspirations as income or wealth thresholds that enter individual utility as "reference points." Those thresholds are determined by an aspirations formation function that depends on both individual achievement and society-wide economic outcomes. Aspirations determine an individual's incentives to invest and bequeath. Our theory captures both the inspiration and the potential frustrations that can result from higher aspirations.

Individual-level behavior can be aggregated to derive the society-wide distribution of income, thus closing the model. This equilibrium interplay between the individual and the social is a central theme of the paper, and a study of society-wide equilibrium leads to additional insights. In the Solow setting with capital stocks in some compact set, steady state distributions must exhibit inequality. When aspirations are socially monotone - nondecreasing in society-wide incomes - a stationary state (which strengthens somewhat the concept of a steady state) must also be bimodal.

Turning to settings which permit sustained growth, we show that the constant-elasticity growth model exhibits history dependence. When aspirations are socially monotone, only one of two outcomes is possible depending on the initial distribution: either convergence to an equal distribution (with growth) or perennial relative divergence with two components, so that everexpanding inequality is the result. The resulting growth rate of per-capita income is strictly lower than the rate achieved under perfect equality.

\footnotetext{
${ }^{29}$ Note that without social monotonicity, it is not necessarily the poorest that are frustrated at any date, but it does follows from the proposition that, once all crossings have ceased, frustration and satisfaction are fully correlated with income, as in Proposition 7. This is consistent, for instance, with the results of Stevenson and Wolfers (2013) who find a significant positive relationship between subjective well-being and income.
} 
Our paper provides a tractable model of aspirations as a socially determined set of reference points. It has allowed us to explore the relationship between aspirations and inequality. We believe that the simplicity of the framework is also conducive to several extensions. We mention a few of interest to us. First, individual aspirations could be a vector of milestones, with the crossing of each milestone "celebrated" by an extra payoff. Higher milestones would become relevant as an individual moves further up the income scale.

More generally, aspirations are multidimensional: not some narrow scalar notion such as wealth, as explored here, but an entire complex that might include education, fertility or social achievement. Developing the model along these lines would tie these ideas in with the notion of capabilities developed by Sen (1985), except that such "capabilities" would, in part, appear as a relativistic construct, inspired by the achievements of others.

A third extension, also influenced in part by the notion of group-based aspirations, would link aspirations to frustration and subsequent violence. Such a model would extend the simple allocative exercise in this paper to a three-way allocation across consumption, productive investment, and resources spent in social conflict. This sort of theory would tie into recent empirical analyses of uneven growth and conflict in developing countries, such as Dube and Vargas (2013) and Mitra and Ray (2014).

To be sure, theories of aspirations and frustration also apply to the economically developed world. There is evidence that technical progress and globalization has led to uneven growth, with large swathes of society left in the wake of that growth. The discontent and frustration apparent in the US and in Europe suggest that such sentiments are partly relativistic, and driven not just by a sense of absolute stagnation. ${ }^{30}$ Our paper belongs to a literature that speaks to such issues. Indeed, if one is willing to take these models more literally, it is possible to use growth incidence curves (say, by decile or percentile), along with controls to account for major policy or regime shifts, to estimate the aspirations-formation process for different societies. If aspirations are largely socially determined, considerations of inequality become paramount. Ensuring that all individuals retain a basic claim on some minimal share of national prosperity, rather than a minimal amount, becomes the deeper policy question that we need to put on center-stage.

\section{REFERENCES}

Acemoglu, Daron. 2002. "Directed Technical Change.” Review of Economic Studies 69:781809.

Acemoglu, Daron and James A Robinson. 2012. Why Nations Fail: The Origins Of Power, Prosperity And Poverty. Crown Business.

Akerlof, George A. and Rachel E. Kranton. 2000. "Economics and Identity." The Quarterly Journal of Economics 115 (3):715-753.

Alonso-Carrera, Jaime, Jordi Caball, and Xavier Raurich. 2007. "Aspirations, Habit Formation, and Bequest Motive.” Economic Journal 117 (520):813-836.

\footnotetext{
${ }^{30}$ Certainly, both absolute and relative considerations play important roles. Easterlin (1974), Frey and Stutzer (2002), Stutzer (2004) and Luttmer (2005) are examples of research that emphasize relativism in happiness. Stevenson and Wolfers (2013) argues that absolute incomes also matter to a large degree.
} 
Appadurai, Arjun. 2004. "The Capacity to Aspire." In Culture and Public Action, edited by Michael Walton and Vijayendra Rao. Stanford, CA: Stanford University Press.

Banerjee, Abhijit and Sendhil Mullainathan. 2010. "The Shape of Temptation: Implications for the Economic Lives of the Poor." NBER Working Papers 15973, NBER.

Banerjee, Abhijit V. and Andrew Newman. 1993. "Occupational Choice and the Process of Development." Journal of Political Economy 101 (2):274-298.

Banerjee, Abhijit V. and Thomas Piketty. 2005. “Top Indian Incomes: 1922-2000.” World Bank Economic Review 19 (1):1-20.

Beaman, Lori, Esther Duflo, Rohini Pande, and Petia Topalova. 2012. "Female Leadership Raises Aspirations and Educational Attainment for Girls: A Policy Experiment in India." Science 335 (6068):582-586.

Becker, Gary, Kevin Murphy, and Ivan Werning. 2005. "The Equilibrium Distribution of Income and the Market for Status." Journal of Political Economy 113:282-301.

Becker, Gary S. and Nigel Tomes. 1979. "An Equilibrium Theory of the Distribution of Income and Intergenerational Mobility." Journal of Political Economy 87 (6):1153-1189.

Berger, Jonah and Devin Pope. 2011. "Can Losing Lead to Winning?" Management Science 57 (5):817-827.

Bernard, Tanguy, Stefan Dercon, Kate Orkin, Alemayehu Seyoum Taffesse et al. 2014. "The future in mind: Aspirations and forward-looking behaviour in rural ethiopia." CSAE conference on economic development in Africa, Oxford, UK, March 25.

Bernheim, B. Douglas, Debraj Ray, and Sevin Yeltekin. 1999. "Self-Control, Saving, and the Low Asset Trap." mimeo, Stanford University.

- 2015. "Poverty and Self-Control." Econometrica 83 (5):1877-1911.

Besley, Timothy. 2015. "Aspirations and the Political Economy of Inequality." mimeographed, London School of Economics.

Bisin, Alberto and Thierry Verdier. 2000. "'Beyond The Melting Pot?': Cultural Transmission, Marriage, and the Evolution of Ethnic and Religious Traits." Quarterly Journal of Economics 115 (3):955-988.

Bogliacino, Francesco and Pietro Ortoleva. 2015. "The Behavior of Others as a Reference Point." Documentos fce-cid escuela de economa n 67, Universidad Nacional de Colombia Sede Bogot.

Bowles, Samuel, Steven N. Durlauf, and Karla Hoff. 2006. Poverty Traps. Princeton University Press.

Brock, W. and L. Mirman. 1972. "Reciprocity in Groups and the Limits to Social Capital." Journal of Economic Theory 4:479-513.

Canova, Fabio. 2004. "Testing for Convergence Clubs in Income Per Capita: A Predictive Density Approach.” International Economic Review 45 (1):49-77.

Carroll, Christopher and David Weil. 1994. "Saving and Growth: A Reinterpretation." CarnegieRochester Conference Series on Public Policy 40:133-192.

Clark, Andrew and Andrew Oswald. 1996. "Satisfaction and Comparison Income." Journal of Public Economics 61:359-381.

Cole, Harold L, George J Mailath, and Andrew Postlewaite. 1992. "Social Norms, Savings Behavior, and Growth.” Journal of Political Economy 100 (6):1092-1125.

Corneo, Giacomo and Olivier Jeanne. 1997. "Conspicuous Consumption, snobbism and conformism." Journal of Public Economics 66:55-71. 
. 1999. "Pecuniary emulation, inequality and growth." European Economic Review 43 (9):1665-1678.

Croix, David de la and Philippe Michel. 2001. "Altruism and Self-Restraint." Annales d'Économie et de Statistique (63):233-259.

Dalton, Patricio, Sayantan Ghosal, and Anandi Mani. 2016. "Poverty and Aspirations Failure." Economic Journal 126:165-188.

Dasgupta, Partha S. and Debraj Ray. 1986. "Inequality as a Determinant of Malnutrition and Unemployment: Theory." Economic Journal 1011-1034.

de Tocqueville, Alexis. 1856. Démocratie en Amérique, L’Ancien Régime et la Révolution. Paris:Robert Laffont.

Deaton, Angus and Jean Drèze. 2002. "Poverty and Inequality in India." Economic and Political Weekly 37:3729-3748.

Drèze, Jean and Amartya Sen. 2013. An Uncertain Glory: India and Its Contradictions. Princeton, NJ: Princeton University Press.

Dube, Oeindrila and Juán Vargas. 2013. "Commodity Price Shocks and Civil Conflict: Evidence from Colombia." Review of Economic Studies 80:1384-1421.

Duesenberry, James S. 1949. Income, Saving and the Theory of Consumer Behavior. Cambridge, MA: Harvard University Press.

Durlauf, Steven and Paul Johnson. 1995. "Multiple Regimes and Cross-Country Growth Behaviour." Journal of Applied Econometrics 10 (2):97-108.

Easterlin, Richard. 1974. "Does Economic Growth Improve the Human Lot? Some Empirical Evidence." In Nations and Households in Economic Growth: Essays in Honor of Moses Abramovitz, edited by Melvin W. Reder Paul A. David. New York: Academic Press.

Esteban, Joan-Mara and Debraj Ray. 2008. "On the Salience of Ethnic Conflict." American Economic Review 98:2185-2202.

Ferrara, Eliana La, Alberto Chong, and Suzanne Duryea. 2012. "Soap Operas and Fertility: Evidence from Brazil." American Economic Journal: Applied Economics 4 (4):1-31.

Frank, Robert. 1985. Choosing the Right Pond: Human Behavior and the quest for status. Oxford University Press, New York.

Freeman, Scott. 1996. "Equilibrium Income Inequality among Identical Agents." Journal of Political Economy 104 (5):1047-1064.

Frey, Bruno S. and Alois Stutzer. 2002. "What Can Economists Learn From Happiness Research?" Journal of Economic Literature 40:402-435.

Galor, Oded and Joseph Zeira. 1993. "Income Distribution and Macroeconomics." Review of Economic Studies 60 (1):35-52.

Genicot, Garance and Debraj Ray. 2009. "Aspirations and Mobility.” Background paper for the lac-regional report on human development 2009, UNDP.

Ghatak, Maitreesh, Parikshit Ghosh, and Ashok Kotwal. 2014. "Growth in the time of UPA: Myths and Reality." Economic and Political Weekly 49:April 19.

Gilboa, Itzhak and David Schmeidler. 1995. "Case-Based Decision Theory." Quarterly Journal of Economics 110 (3):605-639.

Goux, Dominique, Marc Gurgand, and Eric Maurin. 2014. "Adjusting Your Dreams? The Effect of School and Peers on Dropout Behaviour." Discussion Paper 7948, IZA.

Heath, Chip, Richard P. Larrick, and George Wu. 1999. "Goals as Reference Points.” Cognitive Psychology 38:79-109. 
Henderson, Daniel J., Christopher F. Parmeter, and R. Robert Russell. 2008. "Modes, weighted modes, and calibrated modes: evidence of clustering using modality tests." Journal of Applied Econometrics 23 (5):607-638.

Hopkins, Ed and Tatiana Kornienko. 2006. "Inequality and Growth in the Presence of Competition for Status." Economics Letters 93:291-296.

Jensen, Robert and Emily Oster. 2009. "The Power of TV: Cable Television and Women's Status in India." The Quarterly Journal of Economics 124 (3):1057-1094.

Kahneman, Daniel and Amos Tversky. 1979. "Prospect Theory: An Analysis of Decision under Risk." Econometrica 47:263-291.

Karandikar, Rajeeva, Dilip Mookherjee, Debraj Ray, and Fernando Vega-Redondo. 1998. "Evolving Aspirations and Cooperation." Journal of Economic Theory 80:292-331.

Kearney, Melissa S. and Phillip B. Levine. 2014. "Income Inequality, Social Mobility, and the Decision to Drop Out of High School." Working Paper w20195, NBER.

Kőszegi, Botond and Matthew Rabin. 2006. "A Model of Reference-Dependent Preferences." Quarterly Journal of Economics 121.

LeBoeuf, Robyn A. and Zachary Estes. 2004. “"Fortunately, I'm no Einstein”: Comparison Relevance as a Determinant of Behavioral Assimilation and Contrast." Social Cognition $22(6): 607-636$.

Lockwood, Penelope and Ziva Kunda. 1997. "Superstars and Me: Predicting the Impact of Role Models on the Self." Journal of Personality and Social Psychology 73 (1):91-103.

Loury, Glenn. 1981. "Intergenerational Transfers and the Distribution of Earnings." Econometrica 49 (4):843-67. URL http://EconPapers.repec org/RePEc:ecm:emetrp:v:49:y:1981:i:4:p:843-67.

Luttmer, Erzo F. P. 2005. "Neighbors As Negatives: Relative Earnings and Well-Being." Quarterly Journal of Economics 120 (3):963-1002.

Macours, Karen and Renos Vakis. 2009. "Changing Households: Investments and Aspirations through Social Interactions: Evidence from a Randomized Transfer Program." Policy Research Working Paper 5137.

Mani, Anandi, Sendhil Mullainathan, Eldar Shafir, and Jiaying Zhao. 2013. "Poverty Impedes Cognitive Function." Science 341.

Matsuyama, Kiminori. 2004. "Financial Market Globalization, Symmetry-Breaking, and Endogenous Inequality of Nations." Econometrica 72:853-884.

Mitra, Anirban and Debraj Ray. 2014. "Implications of an Economic Theory of Conflict: HinduMuslim Violence in India." Journal of Political Economy 122:719-765.

Mookherjee, Dilip and Debraj Ray. 2003. "Persistent Inequality." Review of Economic Studies $70(2): 369-394$.

Munshi, Kaivan and Jacques Myaux. 2006. "Social Norms and the Fertility Transition." Journal of Development Economics 80:1-38.

Overland, Jody, Christopher D. Carroll, and David N. Weil. 2000. "Saving and Growth with Habit Formation." American Economic Review 90 (3):341-355.

Piketty, Thomas. 2014. Capital in the Twenty First Century. Cambridge, MA: Harvard University Press.

Pittau, Maria Grazia and Roberto Zelli. 2004. "Testing for changing shapes of income distribution: Italian evidence in the 1990s from kernel density estimates." Empirical Economics 29 (2):415-430. 
Pittau, Maria Grazia, Roberto Zelli, and Paul A. Johnson. 2010. "Mixture Models, Convergence Clubs, And Polarization." Review of Income and Wealth 56 (1):102-122.

Quah, Danny. 1993. "Empirical Cross-Section Dynamics in Economic Growth." European Economic Review 37:426-434.

- 1996. "Twin Peaks: Growth and Convergence in Models of Distribution Dynamics." Economic Journal 106:1045-1055.

Ray, Debraj. 1998. Development Economics. Princeton University Press. . 2006. "Aspirations, Poverty and Economic Change." In What Have We Learnt About Poverty, edited by R. Bènabou A. Banerjee and D. Mookherjee. Oxford University Press.

Ray, Debraj and Arthur Robson. 2012. "Status, Intertemporal Choice and Risk-Taking." Econometrica 80:1505-1531.

Robson, Arthur J. 1992. "Status, the Distribution of Wealth, Private and Social Attitudes to Risk." Econometrica 60:837-857.

Sala-i Martin, Xavier. 2006. "The World Distribution of Income: Falling Poverty and ... Convergence, Period.” The Quarterly Journal of Economics 121 (2):351-397.

Schor, Juliet B. 1992. The Overworked American: The Unexpected Decline of Leisure. New York: Basic Books.

Scitovsky, Tibor. 1976. The Joyless Economy. New York: Oxford University Press.

Sen, Amartya. 1985. Commodities and Capabilities. Amsterdam: North Holland.

Shalev, Jonathan. 2000. "Loss aversion equilibrium." International Journal of Game Theory 29 (2):269-287.

Stevenson, Betsey and Justin Wolfers. 2013. "Subjective Well-Being and Income: Is There Any Evidence of Satiation?" American Economic Review 103 (3):598-604.

Stutzer, Alois. 2004. "The Role of Income Aspirations in Individual Happiness." Journal of Economic Behavior and Organization 54:89-109.

Veblen, Thorstein. 1899. "Innovation and Intellectual Property Rights." In The Portable Veblen, edited by M. Lerner. Viking, New York, 53-214.

Zhu, Feng. 2005. "A nonparametric analysis of the shape dynamics of the US personal income distribution: 1962-2000.” Bank for International Settlements W.P. 184.

\section{APPENDIX: PROOFS}

Proof of Proposition 2. By (4), there is an interval $(0, \underline{a}]$ such that aspirations are satisfied when $a \in(0, \underline{a}]$. But $u^{\prime}(0)=\infty$ implies that for $a$ large enough aspirations must be frustrated. Because $w_{1}(z-a)$ is decreasing in $a$, it follows that if aspirations are frustrated at $a$, they are frustrated for $a^{\prime}>a$. So there is a unique $a^{*}>0$ such that aspirations are satisfied for all $a<a^{*}$ and frustrated for all $a>a^{*}$. The first order condition (6) shows that continuation wealth is insensitive to $a$ in all such cases. On the other hand, (7) shows that $z$ is increasing in $a$ as long as aspirations are satisfied.

Proof of Proposition 3. If an individual with $r \equiv a / y$ chooses $g=g(r)>r$, then

$$
\left(1-\frac{g}{\rho}\right)^{1-\sigma}+\delta\left[g^{1-\sigma}+\pi(g-r)^{1-\sigma}\right] \geq\left(1-\frac{g}{\rho}\right)^{1-\sigma}+\delta \underline{g}^{1-\sigma} .
$$


Since the left-hand side is strictly decreasing in $r$, anyone with $r^{\prime}=a^{\prime} / y^{\prime}<a / y$ has satisfied aspirations as well and chooses the growth rate $g\left(r^{\prime}\right)$ that solves (12). Hence, there is a unique $r^{*}$ such that for all pairs $(y, a)$ with $r \equiv a / y>r^{*}$, continuation wealth grows by the factor $g$, and for all $(y, a)$ with $a / y<r^{*}$, continuation wealth grows by the factor $g(a / y)$. Restriction (4) implies that $\underline{g}>1$. It follows trivially that $r^{*}>1$.

By comparing (12) and (13), it is easy to see that $g(r)>g$. Moreover, an inspection of (12) shows that $g(r)$ strictly decreases as $r$ decreases from $r^{*}$. At the same time, $g(r)$ is bounded away from $\underline{g}$ (set $r=0$ in (12) and compare the condition with (13)).

Proof of Observation 1. Consider two incomes $y_{1}$ and $y_{2}$ in the support of $F$, with $y_{2}=\lambda y_{1}$, where $\lambda>1$. If aspirations are socially sensitive, $\Psi\left(y_{2}, F\right)<\Psi\left(y_{2}, \lambda F\right)$, where $\lambda F$ is obtained from $F$ by scaling all incomes up by $\lambda$. It follows that

$$
r\left(y_{2}, F\right)=\frac{y_{2}}{\Psi\left(y_{2}, F\right)}>\frac{y_{2}}{\Psi\left(y_{2}, \lambda F\right)}=\frac{\lambda y_{1}}{\Psi\left(\lambda y_{1}, \lambda F\right)}=\frac{y_{1}}{\Psi\left(y_{1}, F\right)}=r\left(y_{1}, F\right),
$$

where the equality $\frac{\lambda y_{1}}{\Psi\left(\lambda y_{1}, \lambda F\right)}=\frac{y_{1}}{\Psi\left(y_{1}, F\right)}$ follows from scale-invariance.

Proof of Proposition 4. By Observation 1, $r(y)$ decreases in $y$. So, once $r(y)<r^{*}, g(r(y))$ declines in $y$ but is always larger and bounded away from $\underline{g}$ on $y \in(y(a), \infty)$.

Proof of Proposition 5. If $F^{*}$ is concentrated on a single point $y^{*}$; then, by range-boundedness, aspirations $a=y^{*}$. There are two possible optimal choices at $y^{*}$, but neither of these choices can be equal to $a$ itself. For $z=a$ to happen, we must have

$$
w_{0}^{\prime}(a) \geq u^{\prime}(y-k(a)) / f^{\prime}(k(a)),
$$

while at the same time,

$$
w_{0}^{\prime}(a)+w_{1}^{\prime}(0) \leq u^{\prime}(y-k(a)) / f^{\prime}(k(a)) .
$$

Given that $w_{1}^{\prime}(0)>0$, both these inequalities cannot simultaneously hold.

Proof of Proposition 6. First, we show

Lemma 1. If aspirations are scale-invariant and socially monotone, $y_{1}-\Psi\left(y_{1}, F\right) \leq y_{2}-$ $\Psi\left(y_{2}, F\right)$ whenever $y_{2}>y_{1}$ and $y_{1}-\Psi\left(y_{1}, F\right) \geq 0$.

Proof. Consider two incomes $y_{1}$ and $y_{2}$ with $y_{2}>y_{1}$. By Observation $1, \Psi\left(y_{2}, F\right) / y_{2} \leq$ $\Psi\left(y_{1}, F\right) / y_{1}$, so that

$$
\frac{y_{2}-\Psi\left(y_{2}, F\right)}{y_{2}} \geq \frac{y_{1}-\Psi\left(y_{1}, F\right)}{y_{1}} .
$$

Because $y_{2}>y_{1}$ and $y_{1}-\Psi\left(y_{1}, F\right) \geq 0$, the result follows.

We can now proceed with the main proof. Fix a steady state distribution $F$. Consider any two distinct incomes in the support of $F$. We claim that one of them must have unsatisfied aspirations, and is the unique solution to

$$
-\frac{u^{\prime}(y-k(y))}{f^{\prime}(k(y))}+w_{0}^{\prime}(y)=0 .
$$


while the other must have satisfied aspirations, and is the unique solution to

$$
-\frac{u^{\prime}(y-k(y))}{f^{\prime}(k(y))}+w_{0}^{\prime}(y)+w_{1}^{\prime}(y-\Psi(y, F))=0 .
$$

Because the solutions to (14) and (15) are unique (as we shall show), the proof is complete.

The fact that (14) admits a unique solution follows immediately from (5). Next, suppose on the contrary that (15) admits two solutions $y_{1}$ and $y_{2}$, with $y_{1}<y_{2}$. Because aspirations are satisfied at $y_{1}$, we have $y_{1} \geq \Psi\left(y_{1}, F\right)$, so Lemma 1 applies, and $y_{2}-\Psi\left(y_{2}, F\right) \geq y_{1}-\Psi\left(y_{1}, F\right)$. Using the concavity of $w_{1}$, it follows that

$$
w_{1}^{\prime}\left(y_{1}-\Psi\left(y_{1}, F\right)\right) \geq w_{1}^{\prime}\left(y_{2}-\Psi\left(y_{2}, F\right)\right) .
$$

Because (15) holds for both $y_{1}$ and $y_{2}$, we must conclude that

$$
-\frac{u^{\prime}\left(y_{2}-k\left(y_{2}\right)\right)}{f^{\prime}\left(k\left(y_{2}\right)\right)}+w_{0}^{\prime}\left(y_{2}\right) \geq-\frac{u^{\prime}\left(y_{1}-k\left(y_{1}\right)\right)}{f^{\prime}\left(k\left(y_{1}\right)\right)}+w_{0}^{\prime}\left(y_{1}\right)
$$

which contradicts (5).

Define aspirations ratios for each $t$ and $y>0$ by $r_{t}(y) \equiv \Psi\left(y, F_{t}\right) / y$. By Proposition 3, an individual with income $y$ at date $t$ is frustrated if and only if $r_{t}(y)>r^{*}$.

Lemma 2. Assume that aspirations are regular and scale-invariant. Suppose that in any equilibrium, an individual with income $y$ is frustrated at date $t$. Then

(i) If aspirations are socially monotone, then our individual is frustrated at date $t+1$.

(ii) If aspirations are minimally monotone and there are no income crossings over $y$ in the change from date t to $t+1$, then our individual is frustrated at date $t+1$.

Proof. Let $y$ be frustrated under $F_{t}$. Let $F=F_{t}$, and $F^{\prime} \equiv F_{t+\frac{1}{1}}^{1 / g}$; that is, the distribution when all incomes in $F_{t+1}$ are scaled down by $\underline{g}$. By scale invariance,

$$
\Psi\left(\underline{g} y, F_{t+1}\right)=\underline{g} \Psi\left(y, F^{\prime}\right) .
$$

Next, because $g$ is the lowest possible growth factor (Proposition 3 ), $F^{\prime}$ weakly dominates $F$. It follows that if aspirations are socially monotone, then by the continuity of $\Psi$ in $F$,

$$
\Psi\left(y, F^{\prime}\right) \geq \Psi(y, F),
$$

In addition, if there are no income crossings over $y$ in the change over dates $t$ and $t+1$, then $F_{-}^{\prime}(y)=F_{-}(y)$, and the same inequality also holds if aspirations are minimally monotone. Combining (16) and (17), we must conclude that in either case,

$$
r_{t}(y)=\frac{\Psi(y, F)}{y} \leq \Psi\left(\underline{g} y, F_{t+1}\right) \underline{g} y=r_{t+1}(\underline{g} y)
$$

that is, because $y$ is frustrated and moves to $g y$, the aspirations ratio does not fall for $y$ over dates $t$ and $t+1$. We must therefore conclude that his frustration must continue.

Lemma 3. Assume that aspirations are regular and scale-invariant. Suppose that two incomes $y_{0}$ and $y_{0}^{\prime}$, with $y_{0}<y_{0}^{\prime}$, both have satisfied aspirations under the distribution $F_{0}$; that is, $r_{0}\left(y_{0}\right) \leq r^{*}$ and $r_{0}\left(y_{0}^{\prime}\right) \leq r^{*}$. Then $y_{1}<y_{1}^{\prime}$. 
Proof. Consider $y_{0}$ and $y_{0}^{\prime}$ as described in the statement of the Lemma. Because aspirations $a_{0}$ are satisfied at $y_{0},(7)$ applies, and so

$$
w_{0}^{\prime}\left(y_{1}\right)+w_{1}^{\prime}\left(y_{1}-a_{0}\right)=u^{\prime}\left(y_{0}-k\left(z_{0}\right)\right) / f^{\prime}\left(k\left(y_{1}\right)\right) .
$$

By regularity, aspirations at $y_{0}^{\prime}, a_{0}^{\prime}$ are no smaller than $a_{0}$. Inspecting (18), which must also apply to $y_{0}^{\prime}$, and using $y_{0}^{\prime}>y_{0}$, we must conclude from the strict concavity of $w_{0}, w_{1}$ and $u$ (and the weak concavity of $f$ ) that $y_{1}^{\prime}>y_{1}$.

Lemma 4. Assume that aspirations are regular, scale-invariant and range-bound. Then for any distribution $F$ with compact support, the measure of satisfied individuals is positive.

Proof. By (4), $g>1$. It follows that $r^{*}>1$. But because aspirations are range bound, $r(y) \leq 1$ for some income $y$ in the support of $F$. It follows from regularity that $r(y)<r^{*}$ for some set of individuals of positive measure under $F$.

For any $F$, let $y$ be the minimum satisfied person and $\bar{y}$ be the maximum satisfied person. If $\underline{y}>0$, then this infimum is well-defined whenever aspirations are regular. ${ }^{31}$

Lemma 5. Assume that aspirations are regular, scale-invariant and minimally monotone. Suppose that $0<\underline{y}_{t}<\bar{y}_{t}$ at date $t$. Then, $\underline{y}_{t}$ grows faster than $\bar{y}_{t}$ at date $t$.

Proof. By minimal monotonicity and the fact that $\bar{y}_{t}>\underline{y}_{t}$, we have

$$
\Psi\left(\underline{y}_{t}, F_{t}\right)>\Psi\left(\underline{y}_{t}, H^{1}\right)
$$

where $H^{1}$ is obtained from $F_{t}$ by placing the mass $1-F_{t}\left(\underline{y}_{t}\right)$ at $\underline{y}_{t}$, and altering nothing else. Next, define $\eta \equiv \underline{y}_{t} / \bar{y}_{t}<1$. Let $H^{2}$ be derived from $H^{1}$ by scaling every income strictly below $\underline{y}_{t}$ by $\eta$, while leaving the mass at $\underline{y}_{t}$ untouched. By minimal monotonicity,

$$
\Psi\left(\underline{y}_{t}, H^{1}\right) \geq \Psi\left(\underline{y}_{t}, H^{2}\right),
$$

Next, scale every income in $H^{2}$ by $1 / \eta$ to get the distribution $H^{3}$; then by scale-invariance,

$$
\Psi\left(\underline{y}_{t}, H^{2}\right)=\eta \Psi\left(\underline{y}_{t} / \eta, H^{3}\right)=\eta \Psi\left(\bar{y}_{t}, H^{3}\right) .
$$

By construction, $H^{3}$ is just the same as the original distribution $F_{t}$, except that all the mass between $\underline{y}_{t}$ and $\bar{y}_{t}$ has been allocated to the single point $\bar{y}_{t}$. Returning this mass to where it was, and noting that $\bar{y}_{t}$ is the highest income, minimal monotonicity applies again, so that:

$$
\Psi\left(\bar{y}_{t}, H^{3}\right) \geq \Psi\left(\bar{y}_{t}, F_{t}\right) \text {. }
$$

Combining (19)-(22), we see that

$$
\Psi\left(\underline{y}_{t}, F_{t}\right)>\eta \Psi\left(\bar{y}_{t}, F_{t}\right)=\left(\underline{y}_{t} / \bar{y}_{t}\right) \Psi\left(\bar{y}_{t}, F_{t}\right),
$$

or $r_{t}\left(\underline{y}_{t}\right)>r_{t}\left(\bar{y}_{t}\right)$. Apply Proposition 3 to complete the proof.

Lemma 6. Assume that aspirations are regular, scale-invariant and socially monotone. Then in any equilibrium, an individual satisfied at date $t$ is satisfied at date $t+1$.

\footnotetext{
${ }^{31}$ By our convention, a person is satisfied whenever $r(y) \geq r^{*}$. This weak inequality is preserved in the limit given that aspirations are continuous in $y$.
} 
Proof. Define $\underline{r}_{t}$ to be the supremum of aspirations ratios that are no larger than $r^{*}$ under the distribution $F_{t}$, and let $y$ be some income corresponding to this value. By Proposition 3, an individual located at $\underline{y}$ will exhibit the highest growth factor of incomes; call it $\bar{g} \cdot{ }^{32}$ Letting $\underline{r}_{t+1}$ stand for the subsequent aspirations ratio (starting from $\underline{r}_{t}$ ), we then have

$$
\underline{r}_{t}=\frac{\Psi\left(\underline{y}, F_{t}\right)}{\underline{y}}=\frac{\Psi\left(\bar{g} \underline{y}, F_{t}^{\bar{g}}\right)}{\bar{g} \underline{y}} \geq \frac{\Psi\left(\bar{g} \underline{y}, F_{t+1}\right)}{\bar{g} \underline{y}}=\underline{r}_{t+1},
$$

where the second equality follows from scale invariance and the third from social monotonicity (the latter because $F_{t}^{\bar{g}}$ FOSD $F_{t+1}$ ). So

$$
\underline{r}_{t+1} \leq \underline{r}_{t} \leq r^{*} .
$$

Now consider any $y_{t}$ with $r_{t}(y) \leq \underline{r}_{t}$. By Observation 1, we have $y_{t} \geq \underline{y}_{t}$. By Lemma 3, $y_{t+1} \geq \underline{y}_{t+1}{ }^{33}$ Again applying Observation 1, we have $r_{t+1}\left(y_{t+1}\right) \leq \underline{r}_{t+1}$. Combining this observation with (23), we must conclude that

$$
r_{t+1}\left(y_{t+1}\right) \leq \underline{r}_{t+1} \leq \underline{r}_{t} \leq r^{*} .
$$

So aspirations are also satisfied at date $\mathrm{t}+1$ for the person with initial income $y_{t}$.

Proof of Proposition 7. We adopt the innocuous convention that if an individual is indifferent between the higher and lower growth rates, she chooses the higher rate. ${ }^{34}$ We consider three cases:

Case 1: $\inf _{y} r_{0}(y)>r^{*}$. This is ruled out by Lemma 4 .

Case 2: $\sup _{y} r_{0}(y) \leq r^{*}$. Then all individuals are satisfied at date 0 , and so by Lemma 6, will remain satisfied forever. Let $m_{t}$ be the ratio of infimum to supremum incomes at date $t$. By Lemmas 3 and 5, $m_{t}$ is strictly increasing and bounded above by 1 , so it must converge. But in that limit the lowest income must be growing at the same rate as the highest income. By Lemma 5 again, that can only happen if the limit equals 1 . In particular, all aspiration ratios under the sequence $F_{t}$ must converge to 1 . It follows that the growth rate converges to $g(1)$. That $g(1)>1$ follows from inspecting (12) with $r$ set equal to 1.

Case 3: $\inf _{y} r_{0}(y)<r^{*}<\sup _{y} r_{0}(y)$. By Lemma 6, the growth factor of all individuals with $r_{0}(y)>r^{*}$ must be $g$ in all periods. By contrast, every individual with $r_{0}(y) \leq r^{*}$ must grow at a strictly higher rate than $g$; indeed, bounded away from $g$ (Proposition 3 ). That proves that inequality between the frustrated and the satisfied must grow unboundedly high with time. As for those individuals who are satisfied at date 0 , we follow an argument parallel to that for Case 2, using Lemmas 3 and 5 to conclude that $m_{t}$ converges to 1 .

\footnotetext{
${ }^{32}$ We invoke the convention that the upper choice is made at $r^{*}$, in case $\underline{r}_{t}=r^{*}$.

${ }^{33}$ More precisely, this is true from Lemma 3 if $y_{t}>\underline{y}_{t}$. If equality holds, then $y_{t+1}=\underline{y}_{t+1}$, except conceivably when $r\left(y_{t}\right)=r^{*}$, but here we use the convention that the upper solution is chosen.

${ }^{34}$ For the purpose of this proposition, any other convention works just as well, and so does no convention at all, but this simplifies the exposition.
} 
In particular, the limit rate of growth of all satisfied individuals is the same. Denote this limit growth factor by $\bar{g}$. By Proposition 3, we know that $\bar{g}>g$. By range-boundedness, the aspirations ratio of the supremum income is no bigger than 1 , so $\bar{g}=g(\bar{r})$ for some $\bar{r} \leq 1$. By Proposition 3 again, $\bar{g} \leq g(1)$. This proves the very last claim.

Proof of Proposition 8. Suppose Case 3 does not hold, so that there is a date $T$ after which there are no more crossings by positive masses of people. We claim that Case 1 or 2 applies. (That everyone is frustrated is ruled out by Lemma 4.) Lemma 2(ii), states that if there are no income crossings, then a state of frustration will continue in the next period. That tells us that the measure of frustrated individuals under $F_{t}$ is nondecreasing in $t$ for all $t \geq T$, and therefore converges. If it is nonzero, inequality must perennially widen, as all frustrated individuals grow at rate $g$, while all satisfied individuals grow at rates that are larger and bounded away from $g$. That is, we are in the realm of either Case 1 or Case 2.

Finally, convergence of incomes among the satisfied follows from Lemma 5, just as in the proof of Proposition 7. The comparison of growth rates with that in Case 1 also parallels the proof for Proposition 7. 